\title{
The term structure of systematic and idiosyncratic risk
}

Article

Accepted Version

Hollstein, F., Prokopczuk, M. and Wese Simen, C. (2019) The term structure of systematic and idiosyncratic risk. Journal of Futures Markets, 39 (4). pp. 435-460. ISSN 1096-9934 doi: https://doi.org/10.1002/fut.21985 Available at https://centaur.reading.ac.uk/81271/

It is advisable to refer to the publisher's version if you intend to cite from the work. See Guidance on citing.

To link to this article DOI: http://dx.doi.org/10.1002/fut.21985

Publisher: Wiley

All outputs in CentAUR are protected by Intellectual Property Rights law, including copyright law. Copyright and IPR is retained by the creators or other copyright holders. Terms and conditions for use of this material are defined in the End User Agreement.

\section{www.reading.ac.uk/centaur}

\section{CentAUR}

Central Archive at the University of Reading

Reading's research outputs online 


\title{
The Term Structure of Systematic and Idiosyncratic Risk*
}

\author{
Fabian Hollstein ${ }^{\dagger}$, Marcel Prokopczuk ${ }^{\dagger, \ddagger}$, and Chardin Wese Simen ${ }^{\ddagger}$
}

November 5, 2018

\begin{abstract}
We study the term structure of variance (total risk), systematic, and idiosyncratic risk. Consistent with the expectations hypothesis, we find that, for the entire market, the slope of the term structure of variance is mainly informative about the path of future variance. Thus, there is little indication of a time-varying term premium. Turning the focus to individual stocks, we cannot reject the expectations hypothesis for systematic variance, but we strongly reject it for idiosyncratic variance. Our results are robust to jumps and potential statistical biases.
\end{abstract}

\section{JEL classification: G12, G11, G17}

Keywords: Systematic risk, idiosyncratic risk, options, term structure, expectations hypothesis, model-free option-implied variance, implied correlation

\footnotetext{
${ }^{*}$ We are grateful to Bob Webb (the editor); an anonymous associate referee; Alexander Feser (discussant) as well as participants at the meeting of the Swiss Society for Financial Market Research and several seminars for valuable comments. Contact: hollstein@fmt.uni-hannover.de (F. Hollstein), prokopczuk@fmt.uni-hannover.de (M. Prokopczuk), and C.Wese-Simen@icmacentre.ac.uk (C. Wese Simen).

${ }^{\dagger}$ School of Economics and Management, Leibniz University Hannover, Koenigsworther Platz 1, 30167 Hannover, Germany.

${ }^{\ddagger}$ ICMA Centre, Henley Business School, University of Reading, Reading, RG6 6BA, UK.
} 


\section{Introduction}

Recent studies document the predictive power of the term structure of risk-related variables. For example, Vasquez (2016) and Koijen et al. (2017) show that the spread related to option-implied volatilities of different maturities predicts future option returns. At the same time, security exchanges are increasingly disseminating information about the term structure of option-implied volatility. For instance, the Chicago Board Options Exchange (CBOE) now publishes information not only about the popular 1-month VIX but also about the 3-month VIX and the option-implied correlation of various maturities. The academic and professional interest in the term structure of risk raises several questions: What does the term structure of variance tell us about future developments? Are there differences in the term structures of market and stock option prices? Do the term structures of systematic and idiosyncratic risk behave differently? In particular, does the term structure encode information about the future path of the variable of interest or does it instead reflect variations in a possible term premium?

Understanding whether there is a time-varying term premium or not is important in many situations. For asset managers, knowledge about the term premium is essential for strategies that take positions in the long-term variance and roll over short positions in the short-term variance. If the term premium varies over time in a predictable fashion, investors could exploit this. On the other hand, it is important to know whether it is cheaper to hedge against variance increases by buying a long-term variance swap contract or rolling over short-term variance swaps. Understanding the differences in the term structures of systematic and idiosyncratic variance can help asset managers decide how to hedge individual stock variance. Answers to the above questions are also important for risk managers who need an estimate of future stock or market variance. To the extent that there is a time-varying premium in the term structure of variance, the implied forward 
variance will be a noisy proxy for the expected future implied variance. Thus, a risk manager would need to purge the implied forward variance from the time-varying term premium.

This paper analyzes the term structures of total, systematic, and idiosyncratic variance. We formally derive testable predictions of the expectations hypothesis. The expectations hypothesis states that the spread between the current long-term estimate of these risk measures and the current short-term estimate of risk is mainly informative about future developments in short-term risk. Our derivation points to a relationship between the term structure of equity index options prices and that of the option prices on the underlying equities.

We use a large options dataset to empirically test the expectations hypothesis. Our results suggest that the expectations hypothesis generally cannot be rejected for the term structures of the option-implied variance of the market as well as for systematic stock variance. Thus, there is little indication of a time-varying term premium associated with systematic risk. As a consequence, the slope of each term structure is informative about investors' expectations of future short-term (systematic) variance. As opposed to that, we typically detect a negative term premium in the term structure of option-implied idiosyncratic variance. Additionally, we also cannot reject the expectations hypothesis in the term structure of option-implied correlation. These results are robust to the presence of jumps in the underlying price process, as well as potential statistical biases in our tests. We thus conclude that overall the expectations hypothesis provides a good description of the term structure of market option prices, but not to the extent that it accounts for idiosyncratic variance. 
Our work extends the literature on the term structure of variance and volatility. ${ }^{1}$ Campa \& Chang (1995) and Della Corte et al. (2011) study the term structure of foreign exchange variance and volatility, respectively. Mixon (2007) and Johnson (2016) extend these studies to the term structure of equity index implied variance. Our work is related to a study by Heynen et al. (1994), who focus on the term structure of the index and individual equity option-implied volatility. Taken together, the above studies reach conflicting conclusions. These range from a rejection of (an implication of) the expectations hypothesis (Della Corte et al., 2011 and Johnson, 2016) to mixed results (Mixon, 2007) and not being able to reject the expectations hypothesis for the term structure of variance (Heynen et al., 1994 and Campa \& Chang, 1995). Our study is different in several important aspects. First, unlike Heynen et al. (1994), Campa \& Chang (1995), and Mixon (2007), we study the model-free option-implied variance, which makes our results immune to potential misspecification of a specific option pricing model used. That is, we avoid performing a joint test of correct option pricing model specification and the expectations hypothesis. Second, we extend the work of Mixon (2007) and Johnson (2016), who focus on the market index only. Because our derivation points to the link between the optionimplied variances of the index and the individual equities, we study the term structure of the option-implied variance of individual equities. Third, and most importantly, motivated by partly differential results on the market and individual stocks, we decompose the term structure of option-implied variance into systematic and idiosyncratic variance.

Our paper is also related to Clara (2018), who uses the slope of the term structure of beta to predict the cross-section of excess stock returns. Our focus is very different. Our main interest is to understand the term structure of option-implied variance. We

\footnotetext{
${ }^{1}$ Ait-Sahalia et al. (2015) extend the work of Egloff et al. (2010), modeling the term structure of variance swaps in a continuous time setup. Further papers that model the term structure of variance swap rates include Andries et al. (2015), Amengual \& Xiu (2015), Dew-Becker et al. (2017), and Filipović et al. (2016).
} 
use forward-looking betas to decompose the option-implied variance of each stock into systematic and idiosyncratic parts and test the expectations hypothesis for both components.

Feunou et al. (2014) show that principal components from the option-implied variance term structure have predictive power for bond and equity returns. Our results indicate that factors capturing the slope of the term structure on the market level are related to expectations about the future variance and may help rationalize these findings.

We also add to the literature on the term structure of option-implied correlation. Faria \& Kosowski (2016) study the term structure of option-implied correlation. However, they make no attempt to test the expectations hypothesis.

Our study carries implications for asset pricing and risk management in general, and the design of trading strategies in particular. From an asset pricing standpoint, our findings imply, though do not directly test, that the cross-sectional strategies of Vasquez (2016) and Koijen et al. (2017) mainly sort on the expected path of the future short-term option-implied volatility, rather than a related term premium. Thus, our results suggest that these studies capture a risk premium associated with cross-sectional differences in expectations about future short-term risk. Furthermore, our finding that the implied systematic variance term structure mainly reflects expectations about future short-term systematic variance can be used for risk management purposes. Finally, the results presented in this study reveal that a trading strategy that buys the long-term option-implied variance and sells the future short-term option-implied variance is not profitable on average at the market level but yields substantial negative returns when applied to individual stocks.

The remainder of this paper is organized as follows. In Section II, we introduce the data and the methodology for the estimation of the option-implied quantities. In 
Section III, we derive the theoretical relationship between option-implied variances of different maturities and present our empirical results for variance. In Sections IV and V, we separately study the term structure of option-implied systematic and idiosyncratic variance, respectively. We conduct additional analyses and test the robustness of our results in Section VI. Section VII concludes.

\section{Data and Methodology}

\section{A Data}

We obtain monthly options data for all stocks in the S\&P 500 and the corresponding index from IvyDB OptionMetrics for the sample period between January 1996 and August 2015. ${ }^{2}$ We use the Volatility Surface that directly provides implied volatilities over standardized times to maturity for certain levels of delta. ${ }^{3,4}$ We select out-of-the-money options, namely puts with deltas larger than -0.5 and calls with deltas smaller than 0.5 , using constant maturities of $1,3,6,9$, and 12 months for our analysis. Data on the interest rate come from the IvyDB zero coupon yield curve file. ${ }^{5}$ Additionally, we obtain daily return data for the S\&P 500 index and its constituents from the Center for Research in Security Prices (CRSP).

When testing the expectations hypothesis for individual stocks, we require at least 50

\footnotetext{
${ }^{2}$ The starting date of our study aligns with the start of the OptionMetrics database in 1996, while options data were only available up to August 2015 when we started this study, determining the end point of our sample period.

${ }^{3}$ IvyDB uses a kernel smoothing algorithm that generates standardized options only "if there exists enough option price data on that date to accurately interpolate the required values". For more details we refer the interested reader to the IvyDB technical document.

${ }^{4}$ The results are qualitatively similar when directly using "real" options instead of the Volatility Surface.

${ }^{5}$ IvyDB derives the zero coupon yield from the London Interbank Offered Rates (LIBOR) and settlement prices of Chicago Mercantile Exchange Eurodollar futures.
} 
monthly observations to include the firm in the sample. ${ }^{6}$

\section{B Variance, Correlation, and Beta Estimation}

We follow the approach developed by Britten-Jones \& Neuberger (2000) and Jiang \& Tian (2005b) to compute the (annualized) model-free option-implied variance:

$$
\sigma_{j, t, T}^{2}=\frac{2 e^{r_{t}(T-t)}}{T-t} \int_{0}^{\infty} \frac{M_{t}(T, K)}{K^{2}} d K .
$$

$\sigma_{j, t, T}^{2}$ is the (annualized) option-implied variance of asset $j$ for the period starting at time $t$ and ending at time $T$. Note that the option-implied variance is available at time $t . r_{t}$ is the risk-free rate and $T-t$ is the time to maturity of the option, denominated as the fraction of one year. $M_{t}(T, K)$ is the price of the out-of-the-money option (put or call) with strike $K$ and time to maturity $T-t$ at time $t$.

For the empirical implementation, we follow Chang et al. (2012). ${ }^{7}$ First, we compute ex-dividend stock prices. Second, we interpolate implied volatilities on a grid of 1,000 moneyness levels ( $\frac{K}{S}$, strike-to-spot), equally spaced between $0.3 \%$ and $300 \%$, for any given stock and trading day. For implied volatilities outside the range of available strike prices, we extrapolate using the nearest neighbor method (as in Jiang \& Tian, 2005b and Chang et al., 2012). ${ }^{8}$ Using the interpolated volatilities, we compute Black \& Scholes (1973) option prices for calls if $\frac{K}{S}>1$ and puts if $\frac{K}{S}<1$. Third, we use these prices to numerically compute the above integral using a trapezoidal rule (Dennis \& Mayhew, 2002).

\footnotetext{
${ }^{6}$ Overall, we are able to include 658 of the constituents of the S\&P 500, which vary over time due to index additions and deletions.

${ }^{7}$ Given the well-documented issues with the VIX, we decided to follow the methodology described here instead of that used by the CBOE (Jiang \& Tian, 2005a; Andersen et al., 2015).

${ }^{8}$ The OptionMetrics Volatility Surface contains calls with deltas down to 0.20 and puts with deltas ranging up to -0.20 .
} 
For the computation of the option-implied correlation, we follow Driessen et al. (2009), computing the average pairwise correlation among all $N$ stocks in an index:

$$
\rho_{t, T}=\frac{\sigma_{M, t, T}^{2}-\sum_{j=1}^{N} \omega_{j, t}^{2} \sigma_{j, t, T}^{2}}{\sum_{j, l \neq j} \omega_{j, t} \omega_{l, t} \sigma_{j, t, T} \sigma_{l, t, T}} .
$$

$\sigma_{M, t, T}^{2}$ is the (annualized) option-implied variance of the market index and $\omega_{j, t}$ denotes the weight of asset $j$ in the market index at time $t$.

To obtain forward-looking estimates of beta, we use the methodology proposed by Buss \& Vilkov (2012). The Buss \& Vilkov (2012) approach enables us to obtain a term structure of beta. In addition, Hollstein \& Prokopczuk (2016) show that this estimator predicts future realized beta significantly better than all other forward-looking option-implied beta estimators such as those of French et al. (1983), Skintzi \& Refenes (2005), Chang et al. (2012), and Kempf et al. (2015), that would also allow us to obtain information on the term structure of beta. Hollstein \& Prokopczuk (2016) find that the Buss \& Vilkov (2012) estimator predicts future betas even better than the classical historical approach for horizons between one and twelve months. The approach essentially consists in mapping historical correlations, obtained from a 12-month time-series of daily returns, to risk-neutral correlations $\left(\rho_{j l, t, T}\right)$ and combining these estimates with the model-free option-implied volatilities. ${ }^{9}$ A forward-looking estimate for the beta of security $j$ is given by:

$$
\beta_{j, t, T}^{\mathrm{BV}}=\frac{\sigma_{j, t, T} \sum_{l=1}^{N} \omega_{l, t} \sigma_{l, t, T} \rho_{j l, t, T}}{\sigma_{M, t, T}^{2}},
$$

where all variables are as previously defined. The implied volatilities needed for the

\footnotetext{
${ }^{9}$ The authors use (i) the identity that the implied variance of the market index has to be the same as the implied variance of the value-weighted portfolio of all index constituents and (ii) a technical condition that maps physical correlations $\left(\rho_{j l, t, T}^{\mathbb{P}}\right)$ into risk-neutral correlations, namely $\rho_{j l, t, T}=\rho_{j l, t, T}^{\mathbb{P}}-\alpha_{t, T}(1-$ $\left.\rho_{j l, t, T}^{\mathbb{P}}\right)$. Combining these two relations and solving for $\alpha_{t, T}$, the authors recover the implied correlation matrix of a stock index. For further details, we refer the interested reader to the original article.
} 
approach are obtained as the square-root of the option-implied variance extracted from options with time to expiration matching the forecast horizon. We test the robustness of our results to using alternative option-implied beta estimators in Section VI.E.

\section{The Term Structure of Option-Implied Variance}

\section{A Derivation of the Term Structure Relation}

Let $X_{t}$ denote the price of an asset at time $t$. Under no arbitrage, the price should be a semi-martingale. Under the assumption that the price is an Itô semi-martingale and there are jumps of finite variation in the price process, the price dynamics can be expressed as (e.g., Bollerslev \& Todorov, 2011):

$$
\frac{d X_{t}}{X_{t}}=\alpha_{t} d t+v_{t} d W_{t}+\int_{\mathbb{R}}\left(e^{x}-1\right) \tilde{\mu}^{\mathbb{P}}(d t, d x)
$$

$\alpha_{t}$ is the drift and $v_{t}$ is the instantaneous volatility process. $W_{t}$ is a standard Brownian motion. $\quad \tilde{\mu}^{\mathbb{P}}(d t, d x)=\mu(d t, d x)-\nu_{t}^{\mathbb{P}}(d x) d t$ is the compensated jump measure, where

$\mu(d t, d x)$ is a counting measure for the jumps and $\nu_{t}^{\mathbb{P}}(d x) d t$ denotes the compensator of the jumps. The time- $t$ expectation of the quadratic variation of the log price process, $\mathbb{E}_{t}\left(Q V_{j, t, t+k m}\right)$, then solves

$$
\mathbb{E}_{t}\left(Q V_{j, t, t+k m}\right)=\int_{t}^{t+k m} \mathbb{E}_{t}\left(v_{j, \tau}^{2}\right) \mathrm{d} \tau+\int_{t}^{t+k m} \int_{\mathbb{R}} x^{2} \mathbb{E}_{t}\left(v_{t}^{\mathbb{P}}(d \tau, d x)\right)
$$

$\mathbb{E}_{t}\left(Q V_{j, t, t+k m}\right)$ denotes the time- $t$ expectation of the variance of stock $j$ over $k$ periods, each of length $m$ (expressed in months), following time $t . v_{j, \tau}^{2}$ is the instantaneous variance at time $\tau$. Without loss of generality, in the following we set $t=0$. For discrete time 
steps, we have

$$
\frac{1}{k} \sum_{i=0}^{k-1} \mathbb{E}_{0}\left(Q V_{j, i m,(i+1) m}\right)=\mathbb{E}_{0}\left(Q V_{j, 0, k m}\right)
$$

Equation (6) reveals that the long-term implied variance is equal to the mean of time-0 expectations of future short-term implied variances. ${ }^{10}$ Note that this equation holds under both the physical and the risk-neutral probability measures. Under the expectations hypothesis, $\mathbb{E}_{0}\left(Q V_{j, i m,(i+1) m}\right)$ is an unbiased predictor of $\mathbb{E}_{i m}\left(Q V_{j, i m,(i+1) m}\right)$. Hence, we can test the expectations hypothesis by substituting $\mathbb{E}_{0}\left(Q V_{j, i m,(i+1) m}\right)$ with $\mathbb{E}_{i m}\left(Q V_{j, i m,(i+1) m}\right)=$ $\sigma_{j, i m,(i+1) m}^{2}$

Intuitively, Equation (6) implies that an upward-sloping term structure reveals that the market expects the future short-term implied variance to rise and vice versa. Notice also that Equation (6) implies a constant and zero term premium if the expectations hypothesis holds, where the term premium is defined as the return to the strategy that takes a long position in the long-term implied variance and rolls over short positions in the short-term implied variance (see also Section III.C).

Since the level of variance may have a unit root or follow a near-unit-root process, we follow Campa \& Chang (1995) and subtract the short-term option-implied variance on both sides of Equation (6). Hence, we test the expectations hypothesis in the term structure of option-implied variance by estimating the following regression model:

$$
\frac{1}{k} \sum_{i=0}^{k-1}\left(\sigma_{j, i m,(i+1) m}^{2}-\sigma_{j, 0, m}^{2}\right)=a_{j}+b_{j}\left(\sigma_{j, 0, k m}^{2}-\sigma_{j, 0, m}^{2}\right)+\nu_{j, k m}
$$

where $a_{j}$ and $b_{j}$ are the regression intercept and slope, respectively. All other variables are as previously defined. For example, when testing the expectations hypothesis comparing a 12-month variance contract with 12 successive 1 -month contracts, we set $k=12$ and

\footnotetext{
${ }^{10}$ Note that the term $\frac{1}{k}$ in Equation (6) reflects the fact that all variances are annualized.
} 
$m=1$ in Equation (7). ${ }^{11}$

The regression equation above provides several insights. First, the regression slope $b_{j}$ is economically interesting since it reveals the share of variation in the slope of the term structure that relates to future changes in the short-term option-implied variance. The remainder $\left(1-b_{j}\right)$ captures that share of the variation in the slope of the term structure that is related to the variation in the term premium. Notice that if the term premium is zero (constant), as predicted by the expectations hypothesis, we expect $\left(1-b_{j}\right)=0$.

Second, Equation (7) presents two formally testable versions of the expectations hypothesis. The pure version of the expectations hypothesis predicts a zero term premium. We can formally test the pure expectations hypothesis with the joint null hypothesis $a_{j}=0$ and $b_{j}=1$. The general version of the expectations hypothesis instead allows for a non-zero but constant term premium (Cargill, 1975), i.e., the null hypothesis only states $b_{j}=1$. We test the pure expectations hypotheses using a Wald test and the general expectations hypothesis with a $t$-test. For all tests at the market level, we use Newey \& West (1987) corrected standard errors with lag length equal to $k$ times $m$, with $m$ expressed in months.

Finally, to gain power for the tests on the market level, we also perform a joint Wald test across all maturity specifications of both the pure and general expectations hypotheses. Since the residuals are not independent across maturity specifications, we simulate the critical values with a block-bootstrap that also preserves the dependence across maturity specifications. We sample the residuals with replacement in blocks of 12 observations us-

\footnotetext{
${ }^{11}$ Different from, e.g., Campbell \& Shiller (1991), Bekaert \& Hodrick (2001), and Della Corte et al. (2008) we do not use a vector autoregressive (VAR) approach for the expectations hypothesis tests. As noted by Della Corte et al. (2008), in order to set up a VAR for the short-term and long-term variances, one has to make additional assumptions on their data-generating processes (dgp). This implies that the VAR approach is a joint test of the expectations hypothesis and model specification of the dgp. In light of this and the evidence on explosive paths by Downing \& Oliner (2007), we choose not to follow the VAR approach.
} 
ing blocks that begin at the same time across each maturity specification. Afterwards, we create an artificial time-series of the same length as the original one for the expectations hypothesis test, imposing the joint restrictions implied by the pure expectations hypothesis and compute both test statistics. We repeat this step 1,000 times, thus obtaining the distribution of the two test statistics.

For tests on individual stocks, we estimate Equation (7) jointly for all stocks in a panel regression. To perform the inference, we follow the advice of Petersen (2009) and use the two-way clustering approach of Cameron et al. (2011). ${ }^{12}$ We cluster the residuals by both calendar time and firm observations.

\section{B Empirical Results}

Table 1 presents summary statistics on the option-implied variance and correlation for different maturities. In Panel A, we present summary statistics on the market optionimplied variance. We find that the term structure is relatively flat on average and increases only marginally with time to maturity. Since the variance is positive by definition, this preliminary evidence indicates that the average variance term premium is likely small. The 1-month option-implied variance is far more volatile than the 12-month option-implied variance with standard deviations of 0.041 and 0.027 , respectively. The fact that shortterm variance has a higher standard deviation, to some extent, indicates that shocks to variance might be mainly transitory. ${ }^{13}$ The first-order autocorrelation is higher for longer maturities and both skewness and kurtosis decrease with maturity.

Figure 1 shows the evolution of 1-month and 12-month option-implied variance of the

\footnotetext{
${ }^{12}$ If the resulting coefficient covariance matrix is not positive semi-definite, we follow the approach of Higham (1988).

${ }^{13} \mathrm{~A}$ similar pattern across maturities holds for the term structure of interest rates, where shocks cannot easily be considered transitory. It is thus also possible that there is simply more noise in short-term options prices. However, we find further support for our conclusion, e.g., studying Figure 1.
} 
S\&P 500 over time. ${ }^{14}$ There is a large peak during the financial crisis for both maturities. We find that the slope of the term structure, defined as the 12-month minus the 1-month option-implied variance is frequently positive during calm periods, when estimates for the option-implied variance are small. However, the term structure becomes inverted during bad economic times, e.g., during recessions, highlighted by the shaded areas. Taken together, these patterns further strengthen the view that variance shocks are mainly transitory and point towards the presence of mean-reversion in risk-neutral expectations about the future variance.

Panel A of Table 2 reports the results of the test of the expectations hypothesis for the market. We present the results for different pairs of long and short horizons. Several findings are worth noting. First, the slope estimates are generally close to the value of 1 predicted by the expectations hypothesis. For instance, we obtain a slope estimate of 1.042 that is not significantly different from 1 when analyzing 12 months as the long horizon vs. the 12 consecutive 1 -month short horizons. The magnitude of the slope coefficient indicates that the term structure slope is almost exclusively informative about future short-term changes in the option-implied variance. Similar results emerge for other combinations of maturities. Second, the intercept is generally of small economic magnitude and not significantly different from 0 . Third, we formally test the joint restriction implied by the pure expectations hypothesis, i.e., $a=0$ and $b=1$. As the $p$-value associated with the Wald test shows, we cannot reject this null hypothesis. Finally, we also cannot reject the expectations hypothesis based on a joint test across all maturity specifications. We thus conclude that the pure expectations hypothesis provides a good description of the term structure of the market option-implied variance. ${ }^{15}$

\footnotetext{
${ }^{14}$ To enhance the exposition, we plot the longest and the shortest time to maturity only. The variances of intermediate maturities are generally in between those of the 1-month and 12-month maturities.

${ }^{15}$ In a recent related study, Johnson (2016) tests an implication of the expectations hypothesis and rejects it. In Section VI.A, we discuss the relation of his results to ours.
} 
Turning the focus on individual stocks, Panel B of Table 1 presents some key statistics. We obtain the numbers in the table by first averaging over time and then across stocks. We first note that the average level of option-implied variance is substantially higher compared to that of the market. This indicates that a substantial fraction of the optionimplied variance of individual stocks consists of idiosyncratic variance. Furthermore, we find that, on average across stocks, the term structure of the stock option-implied variance is downward-sloping with an average 1-month variance of 0.166 and an average 12-month variance of 0.145 . A similar relation results when value-weighting the stocks. This clear pattern in the option-implied variance across maturities delivers some indication of a negative term premium. The remaining patterns regarding standard deviations, persistence, skewness, and kurtosis across maturities are similar to those of the market index.

Panel B of Table 2 presents our tests of the expectations hypothesis for individual stocks. ${ }^{16}$ These deliver an interesting pattern. For the 12 months vs. 1 month maturity specification, we find a statistically significant positive intercept coefficient of 0.012 and a slope coefficient of 0.909 that is not significantly different from one. The Wald test rejects the pure expectations hypothesis in the term structure of individual stock variance but we cannot reject the general expectations hypothesis. For long overall horizons, we obtain similar results. We are typically able to reject the pure but not the general expectations hypothesis. On the other hand, for short horizons of especially 6 and 3 months, we can strongly reject both the general and the pure expectation hypothesis.

Taken together, although we are not able to reject the expectations hypothesis for the market option-implied variance, Panels $\mathrm{A}$ and $\mathrm{B}$ of Table 2 indicate that there is in general, both for the market and for individual stocks, a decreasing pattern in the

\footnotetext{
${ }^{16}$ Note that for our main results, we restrict both the intercept and slope coefficients to be the same across all stocks. We relax this assumption in Section VI.D.
} 
slope estimates of the term structure of option-implied variance with respect to the time to maturity. To our knowledge, this pattern has not been documented in the previous literature, presenting a new stylized fact in options markets.

A natural question to ask is: does the expectations hypothesis work for some stocks and not others? If so, one possibility is that the firms for which the expectations hypothesis is rejected are small firms with illiquid options. Indeed, when testing the expectations hypothesis separately for each stock, we find that it can only be rejected for part of the stocks while it cannot be rejected for others. Stocks for which we reject the expectations hypothesis are typically small firms relative to the average firm in our sample, have low options trading volumes, and have high average variances. We present these results in Table 3. For example, for the 12 months vs. 1 month maturity specification, the average 1-month and 12-month option-implied variances are 0.19 and 0.16 for stocks for which we reject the pure expectations hypothesis and 0.16 and 0.14 for stocks for which we cannot reject the pure expectations hypothesis, respectively. Furthermore, the average weight in the market index for stocks for which we reject the pure expectations hypothesis is $0.13 \%$ while that for the remaining stocks is $0.22 \%$ on average. Finally, the average daily options volume is 4,412 for stocks for which we reject and 6,117 for the stocks for which we cannot reject the pure expectations hypothesis.

One possible interpretation of these results could be that in the term structure of option prices expectations evolve more consistently for large firms and firms with more liquid options. On the other hand, given that the expectations hypothesis cannot be rejected for the market option-implied variance, it could be that the expectations hypothesis holds for systematic but not for idiosyncratic risk. Thus, the firms for which we are able to reject the expectations hypothesis might simply carry more idiosyncratic risk. In the following sections, we therefore test the expectations hypothesis separately for the systematic and 
idiosyncratic parts of the variance.

\section{Variance Term Premia}

We also examine the return on a strategy that takes a long position in the long-term option-implied variance and rolls over short positions in the short-term option-implied variance. ${ }^{17}$ We compute these returns as

$$
\frac{\sigma_{j, 0, k m}^{2}-\frac{1}{k} \sum_{i=0}^{k-1} \sigma_{j, i m,(i+1) m}^{2}}{\sigma_{j, 0, k m}^{2}}
$$

where all variables are as previously defined. The results of Section III indicate that the variance term premia should be close to zero on average.

We present the results on the variance term premia in Table 4. For example, buying the 12-month option-implied variance and rolling over 12 1-month contracts yields an average annualized return of $1.1 \%$. However, this point estimate is not significantly different from zero. Neither do we obtain a significant average return for any of the other maturity specifications. Hence, on average, there seems to be no variance term premium on the market level.

For the variance term premia of the individual stocks, presented in Panel B of Table 4, the picture looks quite differently. On average across all stocks, the variance term premia are economically and statistically clearly significantly negative. For example when buying a 12-month variance swap contract and rolling over 12 consecutive 1-month contracts, one realizes an average return of $-17 \%$.

\footnotetext{
${ }^{17}$ Note that, in practice, this payoff can be achieved by buying a long-term variance swap and shorting consecutive short-term variance swaps. The payoffs of the floating leg on the long and short positions offset one another.
} 


\section{The Term Structure of Systematic Risk}

\section{A Derivation of the Term Structure Relation}

Bringing together the results of the option-implied variance of the market and the individual stocks, in this section we study the term structure of systematic risk. We find that we cannot reject the expectations hypothesis for the market variance but in part for the variance of individual stocks. A potential explanation for these findings is a differential pattern in the evolution of option-implied systematic and idiosyncratic risk. Thus, in this and Section V, we decompose the variance term structure into its systematic and idiosyncratic components.

While the terms "systematic risk" and "beta" are often used interchangeably, in the following we use the term "systematic risk" to denote the systematic part of the total variance $\left(\beta_{j, t, T}^{2} \sigma_{M, t, T}^{2}\right)$ while beta relates to the standard definition, i.e., the expected covariance of an asset's excess return with that of the market over the expected variance of the market excess return. During our sample period, on average, systematic risk accounts for roughly $40 \%$ of the total variance of individual stocks. ${ }^{18}$ Leading theoretical models predict that the exposure to systematic risk is priced. ${ }^{19}$ Hence, it might be that the expectations hypothesis holds only for systematic risk, while investors pay less attention to the term structure of idiosyncratic risk.

\footnotetext{
${ }^{18}$ For example, for the 1-month horizon, the firm-level average total variance is 0.166 and the average systematic variance $\left(\beta_{j, t, T}^{2} \sigma_{M, t, T}^{2}\right)$ amounts to 0.064 , which corresponds to a share of $38.7 \%$. For the 12 month horizon, the average option-implied variance is 0.145 . The systematic part, on average amounts to 0.063 , which means that it accounts for $43.2 \%$ of the total variance.

${ }^{19}$ Although, recent empirical evidence partly suggests otherwise (e.g., Ang et al., 2006; Herskovic et al., 2016; and Schürhoff \& Ziegler, 2016), which is part of the motivation for why we also examine idiosyncratic risk in the next section.
} 
We assume that asset returns are generated by a single index model of the form

$$
r_{j, t, T}=\alpha_{j, t, T}+\beta_{j, t, T} r_{M, t, T}+\epsilon_{j, t, T},
$$

where $r_{j, t, T}$ and $r_{M, t, T}$ denote the excess returns of stock $j$ and the market for the period $t$ until $T$, respectively. $\epsilon_{j, t, T}$ is the idiosyncratic return component.

In Section A1 of the Appendix, we derive the term structure equation systematic risk under the return generating process of Equation (9) and obtain the following result:

$\frac{1}{k} \sum_{i=0}^{k-1}\left[\mathbb{E}_{0}\left(\beta_{j, i m,(i+1) m}\right)^{2} \mathbb{E}_{0}\left(\sigma_{M, i m,(i+1) m}^{2}\right)\right]+\Delta_{\beta \sigma}+\Delta_{\beta r}+\Delta_{\epsilon}=\mathbb{E}_{0}\left(\beta_{j, 0, k m}\right)^{2} \mathbb{E}_{0}\left(\sigma_{M, 0, k m}^{2}\right)$

$\Delta_{\beta \sigma}, \Delta_{\beta r}$, and $\Delta_{\epsilon}$ are defined in Section A1 of the Appendix.

For testing the expectations hypothesis, we proceed analogously to the case of the option-implied variance and subtract the short-term estimate for systematic risk on both sides of Equation (10), and set up a regression similar to that of Equation (7). An investment strategy on the systematic risk of a firm is realizable much easier than one, e.g., directly on beta. An investor simply needs to compute the forward-looking beta of a stock and trade $\beta^{2}$ shares in the variance of the market index.

\section{B Empirical Results}

In Panel C of Table 1, we present summary statistics on the estimated betas. Naturally, there cannot be a term structure in the value-weighted average since this has to be one for every horizon. Indeed, we find that the value-weighted average is close to one for all horizons. However, there are some differences. The standard deviation, skewness, and kurtosis are generally higher for shorter-term betas while the autocorrelation typically 
increases with time to maturity.

Table 5 shows the results of expectations hypothesis tests in the term structure of systematic risk for individual stocks. ${ }^{20}$ As was the case for the total variance of individual stocks, we detect an intercept coefficient that is positive and significantly different from zero in many cases. We are thus able to reject the pure expectations hypothesis which states that both the intercept should be zero and the slope coefficient should be equal to one at least marginally for all maturity specifications but one. However, the slope coefficients for all horizons are typically close to one, and we are not able to reject the general expectations hypothesis for individual stocks' systematic risk for any of the maturity specifications. Thus, given that we are able to reject the general expectations hypothesis for the total variance of individual stocks especially for short horizons, but not for systematic risk, it appears worthwhile to take another look at the term structure of idiosyncratic variance.

\section{The Term Structure of Idiosyncratic Variance}

\section{A Derivation of the Term Structure Relation}

In the previous sections, we find that the term structure of option-implied variance is downward-sloping on average while the term structure of the market option-implied variance is rather flat. Furthermore, we cannot reject the general expectations hypothesis for systematic risk while the expectations hypothesis does not overall obtain similar support in the term structure of total stock variance. These stylized facts may be indicative of a downward-sloping term structure of option-implied idiosyncratic variance. Thus, in this section, we study the term structure of idiosyncratic variance. We obtain the idiosyn-

\footnotetext{
${ }^{20}$ Note that the results of this section are not entirely model-free since the option-implied beta of Buss \& Vilkov (2012) depends on a parametric model.
} 
cratic variance for all stocks and maturities by solving Equation (A1) of the Appendix for the idiosyncratic variance $\mathbb{E}_{0}\left(\sigma_{\epsilon, t, T}^{2}\right) .{ }^{21}$ We then test the expectations hypothesis for idiosyncratic variance as

$$
\frac{1}{k} \sum_{i=0}^{k-1}\left(\sigma_{\epsilon, j, i m,(i+1) m}^{2}-\sigma_{\epsilon, j, 0, m}^{2}\right)=a_{j}+b_{j}\left(\sigma_{\epsilon, j, 0, k m}^{2}-\sigma_{\epsilon, j, 0, m}^{2}\right)+\nu_{j, k m},
$$

where $\sigma_{\epsilon, j, i m,(i+1) m}^{2}$ denotes the estimate for the option-implied idiosyncratic variance. ${ }^{22}$ All other variables are as previously defined.

\section{B Empirical Results}

In Panel D of Table 1, we present the summary statistics on idiosyncratic variance. Idiosyncratic variance, similar to the total option-implied variance has a slightly downwardsloping term structure on average. Compared to total stock variance, for idiosyncratic variance, the standard deviation, skewness, and kurtosis are reduced, while the autocorrelation is somewhat higher.

In the previous sections, we find that the slope coefficients for the expectations hypothesis tests on systematic risk are typically larger than those for the expectations hypothesis tests on the total stock variance. Thus, given these patterns and the finding that the option-implied variance term structure of individual stocks is typically downward-sloping, we expect the slope coefficients to be below 1 .

We present the results of the expectations hypothesis tests in the term structure of idiosyncratic variance in Table 6. Consistent with our previous results, and as expected,

\footnotetext{
${ }^{21}$ As described in Section A1, we proxy the expected squared market return by the market variance and obtain estimates for the variance of beta and the covariance of beta with the market variance using the full sample estimate.

${ }^{22}$ Note that the decomposition of the total stock variance term structure into a systematic and an idiosyncratic part is not entirely exhaustive. We neglect the parts $\Delta_{\beta \sigma}$ and $\Delta_{\beta r}$ of Equation (10) that are difficult to interpret.
} 
we find that the slope coefficient is clearly below 1 for all maturity combinations. For example, for the 12 months vs. 1 month maturity specification, the slope coefficient is 0.737. For other maturity specifications, the slope coefficients are typically even lower. We are able to strongly reject both the general and the pure expectations hypothesis for all maturity combinations.

Thus, overall we find that the expectations hypothesis cannot be rejected for the market as well as the systematic risk of individual stocks. However, we can strongly reject the expectations hypothesis for idiosyncratic variance.

\section{Idiosyncratic Variance Term Premia}

In the recent years, there has been an extensive literature that studies strategies on idiosyncratic volatility (e.g., Ang et al., 2006, 2009; Fu, 2009; Bekaert et al., 2012). Typically, the authors find that stocks with high past idiosyncratic volatility underperform those stocks with low past idiosyncratic volatility. As opposed to that, in this section, we examine the average term premia on idiosyncratic variance. Instead of sorting the stocks on their past idiosyncratic variance, the strategy considered here takes a long position in the long-term option-implied idiosyncratic variance and rolls over short positions in the short-term option-implied idiosyncratic variance of the same stock. We compute these returns as

$$
\frac{\sigma_{\epsilon, j, 0, k m}^{2}-\frac{1}{k} \sum_{i=0}^{k-1} \sigma_{\epsilon, j, i m,(i+1) m}^{2}}{\sigma_{\epsilon, j, 0, k m}^{2}} .
$$

All variables are as previously defined.

We present the average results in Table $7 .{ }^{23}$ Consistent with the results of the previous subsection, we find that the average idiosyncratic variance term premia are typically

\footnotetext{
${ }^{23}$ To limit the effect of outliers, we winsorize the idiosyncratic variance term premia each month at the $1 \%$ and $99 \%$ quantiles.
} 
negative and significantly different from zero. Hence, buying a long-term position in idiosyncratic stock variance is typically cheaper than rolling over short-term positions. Thus, there is a negative term premium in the term structure of option-implied idiosyncratic variance. Compared to the average total variance term premia for individual stocks, the idiosyncratic variance term premia are even clearly larger in magnitude. Thus, it seems that it is mostly the idiosyncratic part of the stock variance that drives the negative average payoffs.

In the following, we examine the properties of the idiosyncratic variance term premia further. ${ }^{24}$ In Figure 2, we present the time-series of the stock-level average idiosyncratic variance term premia. We find that the stock-level average idiosyncratic variance term premia is volatile, as evidenced by a volatility of 0.688 . It takes particularly low values during two distinct time periods: (i) the Long Term Capital Management (LTCM) crisis followed by the height of the dot-com bubble and (ii) the 2008-2009 financial crisis.

Motivated by the distinct patterns in the time series of average idiosyncratic variance term premia, we analyze the determinants of these in further detail. For so doing, we run a panel regression of idiosyncratic variance term premia on several stock and aggregate time-series characteristics. All characteristics are observed at the same time with the idiosyncratic variance for the long horizon, i.e., at the beginning of the trading period for the idiosyncratic variance term premia. We use the firm size, the book-to-market ratio, the momentum characteristic, and the option volume as potential firm-specific determinants. ${ }^{25}$ We also use the default spread and the term spread as potential aggregate time-series

\footnotetext{
${ }^{24}$ We thank an anonymous referee for suggesting this analysis.

${ }^{25}$ The construction of these variables follows the standard practice in the literature. Size is the stock's market capitalization, obtained from CRSP. The book-to-market ratio uses accounting data from Compustat and is the book value of equity divided by end-of-December market capitalization. We update the book-to-market ratios annually in June, using accounting data from the previous fiscal year. For the momentum signal, we use the return over the period $t-12$ until $t-1$, thus skipping one month. The option volume is the total options volume during the previous month, obtained from OptionMetrics.
} 
determinants of firms' idiosyncratic variance term premia. ${ }^{26}$

The empirical results are presented in Table 8. We find that among the firm characteristics only the book-to-market ratio has a significant effect on variance term premia. These appear to be largely independent of the firm size, the momentum signal, and the option volume. As opposed to that, stocks with higher book-to-market ratios tend to have significantly lower idiosyncratic risk term premia. Thus, it seems that value firms have higher idiosyncratic variance term premia than growth firms.

In contrast to the firm characteristics, we find that both aggregate time-series characteristics, the default premium and the term premium, are significantly positively related to idiosyncratic variance term premia. Thus, overall, particularly crisis-related variables appear to predict idiosyncratic variance term premia. At the first glance, in light of the average results in Figure 2, which indicate that the idiosyncratic variance term premia are especially low preceding or during distressed times, it appears puzzling that both the default spread and the term spread are significantly positively related to idiosyncratic variance term premia. This puzzle gets at least partly resolved by the fact that the book-to-market ratio, which also strongly reacts to economic conditions, is a significantly negative predictor. That the book-to-market ratio influences idiosyncratic variance term premia further indicates that there is some heterogeneity in idiosyncratic variance term premia across firms.

\footnotetext{
${ }^{26}$ We obtain data on the term default spread and the term spread from Amit Goyal's webpage.
} 


\section{Additional Analyses}

\section{A Forward Unbiasedness}

Equation (7) is not the only implication of the expectations hypothesis. The forwardunbiasedness hypothesis, that can also be derived as an implication of Equation (6), states that current forward rates of implied variance should predict future spot rates of implied variance as (Johnson, 2016): ${ }^{27}$

$$
\sigma_{j, m, k m}^{2}-\sigma_{j, 0, m}^{2}=a_{j}+b_{j}\left(f_{j, 0, m, k m}^{2}-\sigma_{j, 0, m}^{2}\right)+\nu_{j, k m}
$$

The forward variance implied by the term structure is obtained as $f_{j, 0, m, k m}^{2}=\sigma_{j, 0, k m}^{2}+$ $\frac{1}{k-1}\left(\sigma_{j, 0, k m}^{2}-\sigma_{j, 0, m}^{2}\right)$. As before, the pure expectations hypothesis predicts $a_{j}=0$ and $b_{j}=1$, while the general expectations hypothesis only states $b_{j}=1$. To thoroughly assess its validity, in this section, we also examine the forward unbiasedness implication of the expectations hypothesis.

We present the results in Table $9 .^{28,29}$ In Panel A, we present the results for the option-implied variance of the market. Overall, the results for the forward unbiasedness formulation of the expectations hypothesis are qualitatively similar to those in Section III. For most of the maturity specifications, we cannot reject the expectations hypothesis. The expectations hypothesis receives the strongest empirical support for long forward horizons of 9 and 6 months. On the other hand, the slope coefficients for the shortest forward horizons is lower. For the 3 months vs. 1 month horizon $(2$ months forward

\footnotetext{
${ }^{27}$ We make use of the expectations hypothesis to substitute $\mathbb{E}_{n}\left(Q V_{j, n, k m}\right)=\sigma_{j, n, k m}^{2}$ for $\mathbb{E}_{0}\left(Q V_{j, n, k m}\right)$.

${ }^{28}$ Note that we only present the results for option-implied variance and not systematic risk, idiosyncratic variance, and correlation. In principle, a forward formulation can also be derived for these term structures. However, in the derivations, the forward beta and correlation contain information that becomes known after $t$ only. Hence, with an unobservable forward rate, the forward unbiasedness hypothesis is not testable.

${ }^{29}$ Note that for this analysis, we additionally use the 2-month option-implied variance contract.
} 
horizon), we even reject the expectations hypothesis in its pure form at $5 \%$ and the general form at $10 \%$. For all other horizons as well as with the joint test, we cannot reject the expectations hypothesis.

Using the aforementioned setup, Johnson (2016) rejects the expectations hypothesis for the market index. There are two core differences between our approach and that of Johnson (2016). First, the author uses daily observations, which induces a substantial amount of overlap, likely introducing an overlapping-observations bias in the analysis. We use monthly observations, which substantially reduces the overlap and makes a bias less likely. On the other hand, moving from daily to monthly observations reduces the sample size and most likely also the statistical power of the test. However, our sample period covers almost 20 years and thus involves 236 monthly observations. Additionally, we address this issue with our joint test that pools observations across maturities. Hence, it is unlikely that our expectations hypothesis tests lack power. Second, Johnson (2016) concentrates on short horizons. Dew-Becker et al. (2017) show that the variance term structure is only upward-sloping at the very short end: There is a large difference between the shortest term implied variance and that with 1-2 months to maturity. Our results of the expectations hypothesis tests are also weaker for short horizons. Thus, these results are ultimately consistent with those of Johnson (2016) and Dew-Becker et al. (2017).

In Panel B of Table 9, we present the results for the forward unbiasedness hypothesis for individual stocks. We can reject both the pure and the general forward unbiasedness hypothesis at least weakly for every horizon. Since we find that we cannot reject the expectations hypothesis for the systematic part of the total stock variance, but strongly reject the expectations hypothesis for the idiosyncratic part, it seems that the forward unbiasedness test loads more strongly on the idiosyncratic part of the stock variance than the test in Section III.B. 
Panel $\mathrm{C}$ of Table 9 presents the results for the forward unbiasedness hypothesis for option-implied idiosyncratic variance. Consistent with our previous results, we find that we can strongly reject both the pure and the general expectations for every maturity specification.

\section{B The Term Structure of Option-Implied Correlation}

In order to further link the evidence on the term structure of the option-implied variance of the market and the individual stocks, we study the term structure of the option-implied correlation. Using the fact that the index is a value-weighted portfolio of its constituents, Equation (6) implies:

$$
\begin{gathered}
\frac{1}{k} \sum_{i=0}^{k-1} \mathbb{E}_{0}\left(\sum_{j=1}^{N} \omega_{j, i m}^{2} Q V_{j, i m,(i+1) m}+\sum_{j, l \neq j} \omega_{j, i m} \omega_{l, i m} \sqrt{Q V}_{j, i m,(i+1) m} \sqrt{Q V}_{l, i m,(i+1) m} \rho_{i m,(i+1) m}\right) \\
\quad=\mathbb{E}_{0}\left(\sum_{j=1}^{N} \omega_{j, 0}^{2} Q V_{j, 0, k m}+\sum_{j, l \neq j} \omega_{j, 0} \omega_{l, 0} \sqrt{Q V}_{j, 0, k m} \sqrt{Q V}_{l, 0, k m} \rho_{0, k m}\right) .
\end{gathered}
$$

$N$ is the number of stocks in the index and $\omega_{j, i m}$ is the market capitalization weight of stock $j$ in the index at time $i m . \quad \rho_{i m,(i+1) m}$ denotes the average correlation of all stocks in the index between times $i m$ and $(i+1) m$, following the definition of Driessen et al. (2009). In Section A2 of the Appendix, we show that Equation (14) implies the following relation between the long-term and short-term expectations about the future option-implied correlation:

$$
\frac{1}{k} \sum_{i=0}^{k-1}\left(\mathbb{E}_{0}\left(\rho_{i m,(i+1) m}\right) \frac{\mathbb{E}_{0}\left(q_{i m,(i+1) m}\right)}{\mathbb{E}_{0}\left(q_{0, k m}\right)}\right)+\Delta_{Q V}+\Delta_{p q}=\mathbb{E}_{0}\left(\rho_{0, k m}\right)
$$

Equation (15) provides several interesting insights. First, it shows that the long-term correlation is informative about (i) the (weighted) expectation about future short-term 
correlations, (ii) the spread between the average long-term and rolled short-term implied variance of individual equities $\left(\Delta_{Q V}\right)$, and (iii) the spread between the long-term and rolled short-term covariances of the option-implied correlation with the weighted cross-sum of option-implied volatilities $\left(\Delta_{p q}\right)$. The expression makes it clear that, contrary to what one might intuitively expect, changes in the term structure of the implied correlations need not be linked to the future path of the implied correlation.

Notice, however, that if the expectations hypothesis holds for individual equities, the second part on the left hand side of Equation (15) is relatively small. ${ }^{30}$ Since Section III.B shows that in some instances we can reject the expectations hypothesis while in others we cannot, it remains an empirical question whether the long-term implied correlation mainly reflects information about the weighted future short-term implied correlation. We formally test the expectations hypothesis in the term structure of the option-implied correlation by running the regression:

$$
\frac{1}{k} \sum_{i=0}^{k-1}\left(\rho_{i m,(i+1) m} \frac{q_{i m,(i+1) m}^{*}}{q_{0, k m}^{*}}-\rho_{0, m}\right)+\hat{\Delta}_{Q V}+\hat{\Delta}_{p q}=a+b\left(\rho_{0, k m}-\rho_{0, m}\right)+\nu_{k m} .
$$

with $q_{t, T}^{*}=\sum_{j, l \neq j} \omega_{j, t} \omega_{l, t}\left(\sigma_{j, t, T} \sigma_{l, t, T}+\operatorname{Cov}_{t}\left(\sigma_{j, t, T}, \sigma_{l, t, T}\right)\right) . \hat{\Delta}_{Q V}$ and $\hat{\Delta}_{p q}$ are defined in Section A2 of the Appendix.

To begin with, Panel E of Table 1 presents summary statistics on the option-implied correlation for different maturities. We find that, on average, the term structure of the option-implied correlation slopes upward. The average over a 1-month horizon amounts to 0.418 , which rises monotonically to 0.490 for the 12 -month horizon. Hence, it seems that participants in the options market expect (i) the correlations to rise in the long run and/or (ii) a negative term premium. As is the case for option-implied variance, we

\footnotetext{
${ }^{30}$ Note that the weights are also potentially time-varying. Thus, changes in long-term implied correlation could also be linked to changes in the index weights.
} 
find the long-horizon option-implied correlation estimates to be more persistent and less volatile, but only slightly less skewed and the kurtosis is close to 3 for all maturities.

Figure 3 presents the time series of option-implied correlation for maturities of 1 and 12 months. We find that the term structure is in general upward-sloping; however, consistent with recent evidence in Faria \& Kosowski (2016), we also find that the term structure of implied correlation flattens during times of economic distress.

Table 10 presents the results for expectations hypothesis tests. ${ }^{31}$ Again, we test both the pure expectations hypothesis, which predicts $a_{j}=0$ and $b_{j}=1$ and the general expectations hypothesis, that only requires $b_{j}=1$. For the 12 months vs. 1 month horizon, we obtain a slope estimate of 0.626 and an intercept estimate of 0.035 . We cannot reject the null of the pure expectations hypothesis. For the remaining horizons, we find that the slope estimates are also generally below 1 , with values between 0.47 and 0.70 . For all horizons, we can neither reject the pure nor the general expectations hypothesis. However, one should notice that the standard errors are relatively large. Thus, our failure to reject might also be driven by a lack of power in the statistical test. To further address the potential lack-of-power issue, we also run a joint test across all maturity specifications. The test shows that we can neither reject the pure nor the general expectations hypothesis in the term structure of option-implied correlation.

\section{The Role of Jumps}

Du \& Kapadia (2013) show that the Britten-Jones \& Neuberger (2000) approach is not robust to the presence of jumps in the underlying price process. Hence, jumps in the

\footnotetext{
${ }^{31}$ One may wonder about the effect of the multiplicative term $\frac{q_{i m,(i+1) m}^{*}}{q_{0, k m}^{*}}$ in Equation (16). For example, the average of the 1 -month $q^{*}$ is 0.115 , while that of the 12 -month $q^{*}$ is 0.107 . The average of fraction when using the $q^{*}$ observed at the same time only is 1.04. Hence, on average, the short-term option-implied correlation is multiplied by a factor slightly above 1 .
} 
price processes might affect the results of our expectations hypothesis tests. To account for this, we repeat our main tests using the option-implied variance following Bakshi et al. (2003), which Du \& Kapadia (2013) show to be empirically robust to jumps. The alternative option-implied variance can be computed as:

$$
\begin{aligned}
\text { QUAD }= & \int_{S}^{\infty} \frac{2\left(1-\ln \left[\frac{K}{S}\right]\right)}{K^{2}} C(T, K) d K \\
& +\int_{0}^{S} \frac{2\left(1+\ln \left[\frac{S}{K}\right]\right)}{K^{2}} P(T, K) d K, \\
\mathrm{CUBIC}= & \int_{S}^{\infty} \frac{6 \ln \left[\frac{K}{S}\right]-3\left(\ln \left[\frac{K}{S}\right]\right)^{2}}{K^{2}} C(T, K) d K \\
& +\int_{0}^{S} \frac{6 \ln \left[\frac{S}{K}\right]+3\left(\ln \left[\frac{S}{K}\right]\right)^{2}}{K^{2}} P(T, K) d K, \\
\text { QUART }= & \int_{S}^{\infty} \frac{12\left(\ln \left[\frac{K}{S}\right]\right)^{2}-4\left(\ln \left[\frac{K}{S}\right]\right)^{3}}{K^{2}} C(T, K) d K \\
& +\int_{0}^{S} \frac{12\left(\ln \left[\frac{S}{K}\right]\right)^{2}+4\left(\ln \left[\frac{S}{K}\right]\right)^{3}}{K^{2}} P(T, K) d K . \\
\mu_{j, t, T}=e^{r_{t}(T-t)}-1- & \frac{e^{r_{t}(T-t)}}{2} \mathrm{QUAD}-\frac{e^{r_{t}(T-t)}}{6} \mathrm{CUBIC}-\frac{e^{r_{t}(T-t)}}{24} \mathrm{QUART}, \\
\sigma_{j, t, T}^{2}=e^{r_{t}(T-t)} \mathrm{QUAD} & -\mu_{j, t, T}^{2},
\end{aligned}
$$

where all variables are as previously defined. We implement the variance computation along the lines outlined in Section II.B.

We present the results for the expectations hypothesis tests using the jump-robust option-implied variance in Tables 11-14. In Table 11, we present the results for the optionimplied variance. For the market, these are qualitatively similar as before. For individual stocks, presented in Panel B of Table 11, with the jump-robust variance estimates we 
are able to reject the general expectations hypothesis also for long horizons. Thus, once we account for jumps, the expectations hypothesis receives only little empirical support anymore in the term structure of individual stock option-implied variance.

For systematic and idiosyncratic risk, presented in Tables 12 and 13, we obtain largely similar results as before. In the case of systematic risk, we can reject the pure expectations hypothesis, but we are typically not able to reject the general expectations hypothesis. For idiosyncratic variance, we are able to reject both the general and pure versions of the expectations hypothesis in each case.

Table 14 presents the results for option-implied correlation. With the jump-robust option-implied variance, the slope coefficients of the expectations hypothesis regression are even further from one than with the standard measure. For all but two maturity specifications we are able to marginally reject the general expectations hypothesis. Thus, overall the expectations hypothesis also receives only little support in the term structure of option-implied correlation.

\section{Firm-Specific Intercept Coefficients}

Note that estimating just one intercept coefficient in a panel regression essentially restricts the intercept coefficient for all stocks to be the same. However, in reality, some stocks might have positive average term premia while others have zero or negative average term premia. In this section, we test the robustness of our main results to this restriction. To do so, we set up a panel regression with firm-fixed intercept coefficients. The Wald test then tests the joint hypothesis that the slope coefficient is equal to one and all intercept coefficients are equal to zero.

We present these results in Tables A1-A3. Overall, these results are largely similar as those without allowing for firm-specific intercepts. We find that in all term structures 
only part of the stocks have intercept coefficients that are significantly different from zero. However, in every instance, the joint Wald test yields a strongly significant rejection of that the "expanded" pure expectations hypothesis, which states that it holds jointly for all stocks.

\section{E Alternative Option-Implied Betas}

Given that previous studies indicate that the Buss \& Vilkov (2012) estimator outperforms all option-implied alternatives, we consider this estimator as a sensible choice for our main analysis. However, to demonstrate the robustness of our results with respect to this choice, we repeat the analysis on the decomposition of the total variance into systematic and idiosyncratic risk. ${ }^{32}$ In particular, we consider the estimators suggested by Skintzi \& Refenes (2005) and Kempf et al. (2015). These two estimators turn out secondand third-best among the option-implied estimators examined in Hollstein \& Prokopczuk (2016).

The option-implied beta based on Skintzi \& Refenes $(2005)\left(\beta_{j, t, T}^{\mathrm{SR}}\right)$ can be obtained as

$$
\beta_{j, t, T}^{\mathrm{SR}}=\frac{\omega_{j, t} \sigma_{j, t, T}^{2}+\sum_{l \neq j} \omega_{l, t} \rho_{t, T} \sigma_{j, t, T} \sigma_{l, t, T}}{\sigma_{M, t, T}^{2}}
$$

where $\rho_{t, T}$ is the option-implied correlation with time-to-maturity $T$. The estimator of

\footnotetext{
${ }^{32}$ In theory, an additional analysis, in which we compute the idiosyncratic variance from a multifactor model, would be very interesting. Unfortunately, this analysis is not practically feasible at the moment. This is because there are currently no options on the size- and value-portfolios traded in the market. Therefore, we do not have any term structure information on the option-implied variances of these factors. Furthermore, in a multifactor model, the betas reflect partial comovement between an explanatory variable and the dependent variable. In this setting, the correlation among the factors becomes important, which further complicates the estimation of factor sensitivities. Unfortunately, there are currently no traded options on the correlation between two risk factors, e.g., the market and size.
} 
Kempf et al. (2015) $\left(\beta_{j, t, T}^{\mathrm{KKS}}\right)$ is

$$
\beta_{j, t, T}^{\mathrm{KKS}}=\frac{\sigma_{j, t, T}}{\sum_{l=1}^{N} \omega_{l, t} \sigma_{l, t, T}}
$$

where all variables are as previously defined.

We present the results for the expectations hypothesis tests for systematic and idiosyncratic risk in Tables A4 and A5 of the Online Appendix. The results are qualitatively very similar to our main results. Rejections of the pure and general expectations hypotheses in the term structure of systematic risk are slightly more frequent. However, given the use of inferior beta estimators, this result does not seem very surprising. For idiosyncratic risk, we can reject the expectations hypothesis in every single case.

\section{F Finite Sample Bias}

We account for possible finite sample bias in the expectations hypothesis tests, as discussed in the literature, e.g., by Bekaert et al. (1997). We address this issue in two steps. First, we study the bias in coefficient estimates. Subsequently, we use a bootstrap approach to infer critical values for the test statistics, avoiding reliance on asymptotic results that may not be valid in finite samples.

To correct the bias in coefficient estimates, we first estimate the regression model of Equation (7). We use the parameter estimates and the time series of residuals to conduct a block-bootstrap of the dependent variable, sampling with replacement from the residuals to create the same number of observations as in the initial regression model. ${ }^{33}$ We run the expectations hypothesis regression of Equation (7) on the simulated data. We repeat this procedure 1,000 times. In a final step, we obtain the finite sample bias as the difference

\footnotetext{
${ }^{33}$ We follow Hall et al. (1995) using a block length of $n^{\frac{1}{3}}$, where $n$ is the total sample size. We use overlapping blocks (Lahiri, 1999).
} 
between the original coefficient estimate and the average of coefficients across the 1,000 simulations. ${ }^{34}$

Second, using the bias-corrected coefficients, we obtain the series of residuals and examine the finite sample properties of the $t$ - and Wald tests. We sample the residuals with replacement and obtain the time series of the dependent variable under the null hypothesis of $a=0$ and $b=1$. We run the regression of Equation (7) and save the values of the test statistics. Again, we repeat this step 1,000 times, thus obtaining the distribution for each of the test statistics. Finally, from the percentiles of the simulated distribution of the test statistics, we obtain the p-values for our expectations hypothesis tests.

We present the empirical results in Table A6 of the Online Appendix. ${ }^{35}$ The results suggest that our main conclusions are robust to potential finite sample bias. The bias in coefficient estimates is negligible throughout. For example, for the option-implied variance of the market, the maximum (absolute) bias in the slope coefficient is -0.24 percentage points, which is far too low to overturn our results on the expectations hypothesis. Turning the focus to finite sample distributions of the test statistics, we also find that the results with the simulated critical values are qualitatively similar to those relying on asymptotic critical values for the test statistics. Hence, it is very unlikely that our main results are significantly affected by finite sample distortions.

\footnotetext{
${ }^{34}$ Efron \& Tibshirani (1986) and Kosowski et al. (2006) show that, typically, the bootstrap results are not sensitive for repetitions larger than 500-1,000. Therefore, we choose 1,000 simulations to limit the computational effort.

${ }^{35}$ To limit the number of tables, we only report the results for option-implied variance. The results on systematic risk and idiosyncratic variance for Sections VI.F and VI.G are qualitatively similar. These results are available upon request.
} 


\section{G Errors-In-Variables}

Finally, we examine the robustness of our results to potential errors-in-variables concerns. To do that, we follow the instrument variable approach of Christensen \& Prabhala (1998). First, we regress the right-hand-side variables on their observation one period before. Subsequently, we replace the right-hand-side variables with their fitted values and run the expectations hypothesis regressions. In the presence of measurement errors in the independent variable, there is a downward attenuation bias in the slope coefficient. Hence, we expect the regression slopes to rise once we use the instrumental variables.

We present the results in Table A7 of the Online Appendix. Consistent with our expectation, we find that the slope coefficients rise in general. Our conclusions, however, remain unchanged.

\section{Conclusion}

This study analyzes the term structure relationship for total, systematic, and idiosyncratic risk. Using model-free option-implied variance estimates, we find evidence in support of the expectations hypothesis for the S\&P 500 market index. Hence, the term structure slope is mainly informative about future changes in the option-implied variance. Second, we test the expectations hypothesis in the term structure of the model-free option-implied variance of individual stocks. We find that the expectations hypothesis results are mixed, although in many instances we reject both the pure and the general expectations hypothesis.

Motivated by the differential results for the market and individual stocks, we further decompose the variance term structure, separately studying systematic and idiosyncratic risk. We find that the term structures of these variables are behaved differently. Consistent 
with the results for the market, we cannot reject the general expectations hypothesis for systematic risk while we strongly reject the expectations hypothesis for idiosyncratic risk. Thus, our results suggest that systematic risk evolves consistently over time while there are large and time-varying negative term premia for idiosyncratic risk. Buying long-term market or systematic risk contracts on average yields similar results as rolling over shortterm contracts, while for idiosyncratic variance contracts rolling over short-term contracts is considerably more expensive. 


\section{Technical Appendix: Derivations}

\section{A1 Systematic Risk and Beta}

It is straightforward to show that the return generating process of Equation (9) implies: ${ }^{36}$

$$
\begin{aligned}
\mathbb{E}_{0}\left(\operatorname{Var}_{t, T}\left(\alpha_{j}+\beta_{j} r_{M}+\epsilon_{j}\right)\right)= & \mathbb{E}_{0}\left(\beta_{j, t, T}\right)^{2} \mathbb{E}_{0}\left(\sigma_{M, t, T}^{2}\right)+\operatorname{Var}_{0}\left(\beta_{j, t, T}\right) \mathbb{E}_{0}\left(\sigma_{M, t, T}^{2}\right) \\
& +\operatorname{Cov}_{0}\left(\beta_{j, t, T}^{2}, r_{M, t, T}^{2}\right)+\mathbb{E}_{0}\left(\sigma_{\epsilon, t, T}^{2}\right) .
\end{aligned}
$$

$\mathbb{E}_{t, T}(\cdot), \operatorname{Var}_{t, T}(\cdot)$, and $\operatorname{Cov}_{t, T}(\cdot)$ are the conditional time- $t$ expectations, variance, and covariance operators for the period $t$ until $T$, respectively. To empirically implement the expectations hypothesis test, we proxy the expected squared market return by the market variance. Finally, we obtain estimates for the time- $t$ variance of beta and covariance of beta with the market variance using the full sample estimate. Inserting the relation of Equation (A1) into Equation (6), we get

$$
\begin{aligned}
\frac{1}{k} \sum_{i=0}^{k-1} & {\left[\mathbb{E}_{0}\left(\beta_{j, i m,(i+1) m}\right)^{2} \mathbb{E}_{0}\left(\sigma_{M, i m,(i+1) m}^{2}\right)+\operatorname{Var}_{0}\left(\beta_{j, i m,(i+1) m}\right) \mathbb{E}_{0}\left(\sigma_{M, i m,(i+1) m}^{2}\right)\right.} \\
& \left.+\operatorname{Cov}_{0}\left(\beta_{j, i m,(i+1) m}^{2}, r_{M, i m,(i+1) m}^{2}\right)+\mathbb{E}_{0}\left(\sigma_{\epsilon, i m,(i+1) m}^{2}\right)\right]=\mathbb{E}_{0}\left(\beta_{j, 0, k m}\right)^{2} \mathbb{E}_{0}\left(\sigma_{M, 0, k m}^{2}\right) \\
& +\operatorname{Var}_{0}\left(\beta_{j, 0, k m}\right) \mathbb{E}_{0}\left(\sigma_{M, 0, k m}^{2}\right)+\operatorname{Cov}_{0}\left(\beta_{j, 0, k m}^{2}, r_{M, 0, k m}^{2}\right)+\mathbb{E}_{0}\left(\sigma_{\epsilon, 0, k m}^{2}\right) .
\end{aligned}
$$

\footnotetext{
${ }^{36} \mathrm{We}$ assume continuous time, that $\alpha_{j, t, T}$ is constant for each period, and that $\epsilon_{j, t, T}$ is independent of $\beta_{j, t, T} r_{M, t, T}$. Using $\mathbb{E}_{0}\left(\operatorname{Var}_{t, T}\left(\alpha_{j}+\beta_{j} r_{M}+\epsilon_{j}\right)\right)=\mathbb{E}_{0}\left(\operatorname{Var}_{t, T}\left(\beta_{j} r_{M}+\epsilon_{j}\right)\right)=$ $\mathbb{E}_{0}\left(\mathbb{E}_{t, T}\left(\left(\beta_{j} r_{M}+\epsilon_{j}\right)^{2}\right)-\mathbb{E}_{t, T}\left(\left(\beta_{j} r_{M}+\epsilon_{j}\right)\right)^{2}\right)$ and accounting for the fact that the squared expectation part is negligible for a continuous time process, one can easily derive Equation (A1).
} 
Collecting terms on the left hand side of the equality sign, we obtain:

$$
\begin{aligned}
\frac{1}{k} \sum_{i=0}^{k-1} & {\left[\mathbb{E}_{0}\left(\beta_{j, i m,(i+1) m}\right)^{2} \mathbb{E}_{0}\left(\sigma_{M, i m,(i+1) m}^{2}\right)\right]-\operatorname{Var}_{0}\left(\beta_{j, 0, k m}\right) \mathbb{E}_{0}\left(\sigma_{M, 0, k m}^{2}\right) } \\
& +\frac{1}{k} \sum_{i=0}^{k-1}\left[\operatorname{Var}_{0}\left(\beta_{j, i m,(i+1) m}\right) \mathbb{E}_{0}\left(\sigma_{M, i m,(i+1) m}^{2}\right)\right]-\operatorname{Cov}_{0}\left(\beta_{j, 0, k m}^{2}, r_{M, 0, k m}^{2}\right) \\
& +\frac{1}{k} \sum_{i=0}^{k-1}\left[\operatorname{Cov}_{0}\left(\beta_{j, i m,(i+1) m}^{2}, r_{M, i m,(i+1) m}^{2}\right)\right]-\mathbb{E}_{0}\left(\sigma_{\epsilon, 0, k m}^{2}\right) \\
& +\frac{1}{k} \sum_{i=0}^{k-1}\left[\mathbb{E}_{0}\left(\sigma_{\epsilon, i m,(i+1) m}^{2}\right)\right]=\mathbb{E}_{0}\left(\beta_{j, 0, k m}\right)^{2} \mathbb{E}_{0}\left(\sigma_{M, 0, k m}^{2}\right) .
\end{aligned}
$$

Defining $\Delta_{\beta \sigma}=\frac{1}{k} \sum_{i=0}^{k-1}\left[\operatorname{Var}_{0}\left(\beta_{j, i m,(i+1) m}\right) \mathbb{E}_{0}\left(\sigma_{M, i m,(i+1) m}^{2}\right)\right]-\operatorname{Var}_{0}\left(\beta_{j, 0, k m}\right) \mathbb{E}_{0}\left(\sigma_{M, 0, k m}^{2}\right)$, $\Delta_{\beta r}=\frac{1}{k} \sum_{i=0}^{k-1}\left[\operatorname{Cov}_{0}\left(\beta_{j, i m,(i+1) m}^{2}, r_{M, i m,(i+1) m}^{2}\right)\right]-\operatorname{Cov}_{0}\left(\beta_{j, 0, k m}^{2}, r_{M, 0, k m}^{2}\right), \quad$ and $\Delta_{\epsilon}=\frac{1}{k} \sum_{i=0}^{k-1}\left[\mathbb{E}_{0}\left(\sigma_{\epsilon, i m,(i+1) m}^{2}\right)\right]-\mathbb{E}_{0}\left(\sigma_{\epsilon, 0, k m}^{2}\right)$, we obtain:

$\frac{1}{k} \sum_{i=0}^{k-1}\left[\mathbb{E}_{0}\left(\beta_{j, i m,(i+1) m}\right)^{2} \mathbb{E}_{0}\left(\sigma_{M, i m,(i+1) m}^{2}\right)\right]+\Delta_{\beta \sigma}+\Delta_{\beta r}+\Delta_{\epsilon}=\mathbb{E}_{0}\left(\beta_{j, 0, k m}\right)^{2} \mathbb{E}_{0}\left(\sigma_{M, 0, k m}^{2}\right)$

\section{A2 Option-Implied Correlation}

Re-arranging Equation (14), we obtain:

$$
\begin{aligned}
& \frac{1}{k} \sum_{i=0}^{k-1}\left(\mathbb{E}_{0}\left(\rho_{i m,(i+1) m}\right) \frac{\mathbb{E}_{0}\left(q_{i m,(i+1) m}\right)}{\mathbb{E}_{0}\left(q_{0, k m}\right)}\right) \\
& -\frac{\mathbb{E}_{0}\left(\sum_{j=1}^{N} \omega_{j, 0}^{2} Q V_{j, 0, k m}\right)-\frac{1}{k} \sum_{i=0}^{k-1}\left(\mathbb{E}_{0}\left(\sum_{j=1}^{N} \omega_{j, i m}^{2} Q V_{j, i m,(i+1) m}\right)\right)}{\mathbb{E}_{0}\left(q_{0, k m}\right)} \\
& -\frac{\operatorname{Cov}_{0}\left(\rho_{0, k m}, q_{0, k m}\right)-\frac{1}{k} \sum_{i=0}^{k-1}\left(\operatorname{Cov}_{0}\left(\rho_{i m,(i+1) m}, q_{i m,(i+1) m}\right)\right)}{\mathbb{E}_{0}\left(q_{0, k m}\right)}=\mathbb{E}_{0}\left(\rho_{0, k m}\right),
\end{aligned}
$$

with $q_{t, T}=\sum_{j, l \neq j} \omega_{j, t} \omega_{l, t} \sqrt{Q V_{j, t, T}} \sqrt{Q V}_{l, t, T}$ and $\mathbb{E}_{0}\left(q_{t, T}\right)=\sum_{j, l \neq j} \mathbb{E}_{0}\left(\omega_{j, t}\right) \mathbb{E}_{0}\left(\omega_{l, t}\right)$ $\left(\mathbb{E}_{0}\left(\sqrt{Q V}_{j, t, T}\right) \mathbb{E}_{0}\left(\sqrt{Q V}_{l, t, T}\right)+\operatorname{Cov}_{0}\left(\sqrt{Q V}_{j, t, T}, \sqrt{Q V}_{l, t, T}\right)\right) .{ }^{37}$

Defining

\footnotetext{
${ }^{37} \mathrm{We}$ assume that the weights are independent of the quadratic variations.
} 
$\Delta_{Q V} \quad=\quad-\frac{\mathbb{E}_{0}\left(\sum_{j=1}^{N} \omega_{j, 0}^{2} Q V_{j, 0, k m}\right)-\frac{1}{k} \sum_{i=0}^{k-1}\left(\mathbb{E}_{0}\left(\sum_{j=1}^{N} \omega_{j, i m}^{2} Q V_{j, i m,(i+1) m}\right)\right)}{\mathbb{E}_{0}\left(q_{0, k m}\right)}$ and $\Delta_{p q}=-\frac{\operatorname{Cov}_{0}\left(\rho_{0, k m}, q_{0, k m}\right)-\frac{1}{k} \sum_{i=0}^{k-1}\left(\operatorname{Cov}_{0}\left(\rho_{i m,(i+1) m}, q_{i m,(i+1) m}\right)\right)}{\mathbb{E}_{0}\left(q_{0, k m}\right)}$, Equation A5 reads:

$$
\frac{1}{k} \sum_{i=0}^{k-1}\left(\mathbb{E}_{0}\left(\rho_{i m,(i+1) m}\right) \frac{\mathbb{E}_{0}\left(q_{i m,(i+1) m}\right)}{\mathbb{E}_{0}\left(q_{0, k m}\right)}\right)+\Delta_{Q V}+\Delta_{p q}=\mathbb{E}_{0}\left(\rho_{0, k m}\right) .
$$

We formally test the expectations hypothesis in the term structure of the optionimplied correlation by running the regression:

$$
\begin{aligned}
& \frac{1}{k} \sum_{i=0}^{k-1}\left(\rho_{i m,(i+1) m} \frac{q_{i m,(i+1) m}^{*}}{q_{0, k m}^{*}}-\rho_{0, m}\right)+\frac{\frac{1}{k} \sum_{i=0}^{k-1}\left(\sum_{j=1}^{N} \omega_{j, i m}^{2} \sigma_{j, i m,(i+1) m}^{2}\right)-\sum_{j=1}^{N} \omega_{j, 0}^{2} \sigma_{j, 0, k m}^{2}}{q_{0, k m}^{*}} \\
& \quad+\frac{\frac{1}{k} \sum_{i=0}^{k-1}\left(\operatorname{Cov}_{i m}\left(\rho_{i m,(i+1) m}, q_{i m,(i+1) m}^{*}\right)\right)-\operatorname{Cov}_{0}\left(\rho_{0, k m}, q_{0, k m}^{*}\right)}{q_{0, k m}^{*}} \\
& \quad=a+b\left(\rho_{0, k m}-\rho_{0, m}\right)+\nu_{k m},
\end{aligned}
$$

with $q_{t, T}^{*}=\sum_{j, l \neq j} \omega_{j, t} \omega_{l, t}\left(\sigma_{j, t, T} \sigma_{l, t, T}+\operatorname{Cov}_{t}\left(\sigma_{j, t, T}, \sigma_{l, t, T}\right)\right)$.

$$
\text { Defining } \quad \hat{\Delta}_{Q V} \quad \frac{\frac{1}{k} \sum_{i=0}^{k-1}\left(\sum_{j=1}^{N} \omega_{j, i m}^{2} \sigma_{j, i m,(i+1) m}^{2}\right)-\sum_{j=1}^{N} \omega_{j, 0}^{2} \sigma_{j, 0, k m}^{2}}{q_{0, k m}^{*}} \quad \text { and }
$$

$\hat{\Delta}_{p q}=\frac{\frac{1}{k} \sum_{i=0}^{k-1}\left(\operatorname{Cov}_{i m}\left(\rho_{i m,(i+1) m}, q_{m,(i+1) m}^{*}\right)\right)-\operatorname{Cov}_{0}\left(\rho_{0, k m}, q_{0, k m}^{*}\right)}{q_{0, k m}^{*}}$, we obtain the equation presented in the main text:

$$
\frac{1}{k} \sum_{i=0}^{k-1}\left(\rho_{i m,(i+1) m} \frac{q_{i m,(i+1) m}^{*}}{q_{0, k m}^{*}}-\rho_{0, m}\right)+\hat{\Delta}_{Q V}+\hat{\Delta}_{p q}=a+b\left(\rho_{0, k m}-\rho_{0, m}\right)+\nu_{k m} .
$$




\section{References}

Ait-Sahalia, Y., Karaman, M., \& Mancini, L. (2015). The term structure of variance swaps and risk premia. NBER Working Paper.

Amengual, D., \& Xiu, D. (2015). Resolution of policy uncertainty and sudden declines in volatility. Chicago Booth Working Paper.

Andersen, T. G., Bondarenko, O., \& Gonzalez-Perez, M. T. (2015). Exploring return dynamics via corridor implied volatility. Review of Financial Studies, 28(10), 29022945 .

Andries, M., Eisenbach, T., Schmalz, M., \& Wang, Y. (2015). Price vs. quantity in the term structure of variance risk premia. Working Paper, University of Toulouse.

Ang, A., Hodrick, R. J., Xing, Y., \& Zhang, X. (2006). The cross-section of volatility and expected returns. Journal of Finance, 61(1), 259-299.

Ang, A., Hodrick, R. J., Xing, Y., \& Zhang, X. (2009). High idiosyncratic volatility and low returns: International and further US evidence. Journal of Financial Economics, $91(1), 1-23$.

Bakshi, G., Kapadia, N., \& Madan, D. (2003). Stock return characteristics, skew laws, and the differential pricing of individual equity options. Review of Financial Studies, $16(1), 101-143$.

Bekaert, G., \& Hodrick, R. J. (2001). Expectations hypotheses tests. Journal of Finance, $56(4), 1357-1394$.

Bekaert, G., Hodrick, R. J., \& Marshall, D. A. (1997). On biases in tests of the expectations hypothesis of the term structure of interest rates. Journal of Financial Economics, $44(3), 309-348$.

Bekaert, G., Hodrick, R. J., \& Zhang, X. (2012). Aggregate idiosyncratic volatility. Journal of Financial and Quantitative Analysis, 47(6), 1155-1185.

Black, F., \& Scholes, M. (1973). The pricing of options and corporate liabilities. Journal of Political Economy, 81(3), 637-654.

Bollerslev, T., \& Todorov, V. (2011). Tails, fears, and risk premia. Journal of Finance, $66(6), 2165-2211$.

Britten-Jones, M., \& Neuberger, A. (2000). Option prices, implied price processes, and stochastic volatility. Journal of Finance, 55(2), 839-866.

Buss, A., \& Vilkov, G. (2012). Measuring equity risk with option-implied correlations. Review of Financial Studies, 25(10), 3113-3140. 
Cameron, A. C., Gelbach, J. B., \& Miller, D. L. (2011). Robust inference with multiway clustering. Journal of Business \& Economic Statistics, 29(2), 238-249.

Campa, J., \& Chang, P. K. (1995). Testing the expectations hypothesis on the term structure of volatilities in foreign exchange options. Journal of Finance, 50(2), 529547.

Campbell, J. Y., \& Shiller, R. J. (1991). Yield spreads and interest rate movements: A bird's eye view. Review of Economic Studies, 58(3), 495-514.

Cargill, T. F. (1975). The term structure of interest rates: A test of the expectations hypothesis. Journal of Finance, 30(3), 761-771.

Chang, B.-Y., Christoffersen, P., Jacobs, K., \& Vainberg, G. (2012). Option-implied measures of equity risk. Review of Finance, 16(2), 385-428.

Christensen, B. J., \& Prabhala, N. R. (1998). The relation between implied and realized volatility. Journal of Financial Economics, 50(2), 125-150.

Clara, N. (2018). The term-structure of systematic risk. London Business School Working Paper.

Della Corte, P., Sarno, L., \& Thornton, D. L. (2008). The expectation hypothesis of the term structure of very short-term rates: Statistical tests and economic value. Journal of Financial Economics, 89(1), 158-174.

Della Corte, P., Sarno, L., \& Tsiakas, I. (2011). Spot and forward volatility in foreign exchange. Journal of Financial Economics, 100(3), 496-513.

Dennis, P., \& Mayhew, S. (2002). Risk-neutral skewness: Evidence from stock options. Journal of Financial and Quantitative Analysis, 37(3), 471-493.

Dew-Becker, I., Giglio, S., Le, A., \& Rodriguez, M. (2017). The price of variance risk. Journal of Financial Economics, 123(2), 225-250.

Downing, C., \& Oliner, S. (2007). The term structure of commercial paper rates. Journal of Financial Economics, 83(1), 59-86.

Driessen, J., Maenhout, P. J., \& Vilkov, G. (2009). The price of correlation risk: Evidence from equity options. Journal of Finance, 64(3), 1377-1406.

Du, J., \& Kapadia, N. (2013). The tail in the volatility index. EFA Meetings 2013 Working Paper.

Efron, B., \& Tibshirani, R. (1986). Bootstrap methods for standard errors, confidence intervals, and other measures of statistical accuracy. Statistical Science, 1(1), 54-75. 
Egloff, D., Leippold, M., \& Wu, L. (2010). The term structure of variance swap rates and optimal variance swap investments. Journal of Financial and Quantitative Analysis, $45(5), 1279-1310$.

Faria, G., \& Kosowski, R. (2016). The correlation risk premium term structure. EFA Meetings 2016 Working Paper.

Feunou, B., Fontaine, J.-S., Taamouti, A., \& Tédongap, R. (2014). Risk premium, variance premium, and the maturity structure of uncertainty. Review of Finance, 18(1), 219-269.

Filipović, D., Gourier, E., \& Mancini, L. (2016). Quadratic variance swap models. Journal of Financial Economics, 119(1), 44-68.

French, D. W., Groth, J. C., \& Kolari, J. W. (1983). Current investor expectations and better betas. Journal of Portfolio Management, 10(1), 12-17.

$\mathrm{Fu}, \mathrm{F}$. (2009). Idiosyncratic risk and the cross-section of expected stock returns. Journal of Financial Economics, 91 (1), 24-37.

Hall, P., Horowitz, J. L., \& Jing, B.-Y. (1995). On blocking rules for the bootstrap with dependent data. Biometrika, 82(3), 561-574.

Herskovic, B., Kelly, B., Lustig, H., \& Van Nieuwerburgh, S. (2016). The common factor in idiosyncratic volatility: Quantitative asset pricing implications. Journal of Financial Economics, 119(2), 249-283.

Heynen, R., Kemna, A., \& Vorst, T. (1994). Analysis of the term structure of implied volatilities. Journal of Financial and Quantitative Analysis, 29(1), 31-56.

Higham, N. J. (1988). Computing a nearest symmetric positive semidefinite matrix. Linear Algebra and its Applications, 103, 103-118.

Hollstein, F., \& Prokopczuk, M. (2016). Estimating beta. Journal of Financial and Quantitative Analysis, 51(4), 1437-1466.

Jiang, G., \& Tian, Y. (2005a). Gauging the investor fear gauge: Implementation problems in the CBOE's new volatility index and a simple solution. York University Working Paper.

Jiang, G. J., \& Tian, Y. S. (2005b). The model-free implied volatility and its information content. Review of Financial Studies, 18(4), 1305-1342.

Johnson, T. L. (2016). Risk premia and the VIX term structure. Journal of Financial and Quantitative Analysis, forthcoming.

Kempf, A., Korn, O., \& Saßning, S. (2015). Portfolio optimization using forward-looking information. Review of Finance, 19(1), 467-490. 
Koijen, R. S., Moskowitz, T. J., Pedersen, L. H., \& Vrugt, E. B. (2017). Carry. Journal of Financial Economics, forthcoming.

Kosowski, R., Timmermann, A., Wermers, R., \& White, H. (2006). Can mutual fund "stars" really pick stocks? New evidence from a bootstrap analysis. Journal of Finance, $61(6), 2551-2595$.

Lahiri, S. N. (1999). Theoretical comparisons of block bootstrap methods. Annals of Statistics, 27, 386-404.

Mixon, S. (2007). The implied volatility term structure of stock index options. Journal of Empirical Finance, 14(3), 333-354.

Newey, W. K., \& West, K. D. (1987). A simple, positive semi-definite, heteroskedasticity and autocorrelation consistent covariance matrix. Econometrica, 55(3), 703-708.

Petersen, M. A. (2009). Estimating standard errors in finance panel data sets: Comparing approaches. Review of Financial Studies, 22(1), 435-480.

Schürhoff, N., \& Ziegler, A. (2016). Variance risk, financial intermediation, and the crosssection of expected option returns. CEPR Working Paper.

Skintzi, V. D., \& Refenes, A.-P. N. (2005). Implied correlation index: A new measure of diversification. Journal of Futures Markets, 25(2), 171-197.

Vasquez, A. (2016). Equity volatility term structures and the cross-section of option returns. Journal of Financial and Quantitative Analysis, forthcoming. 


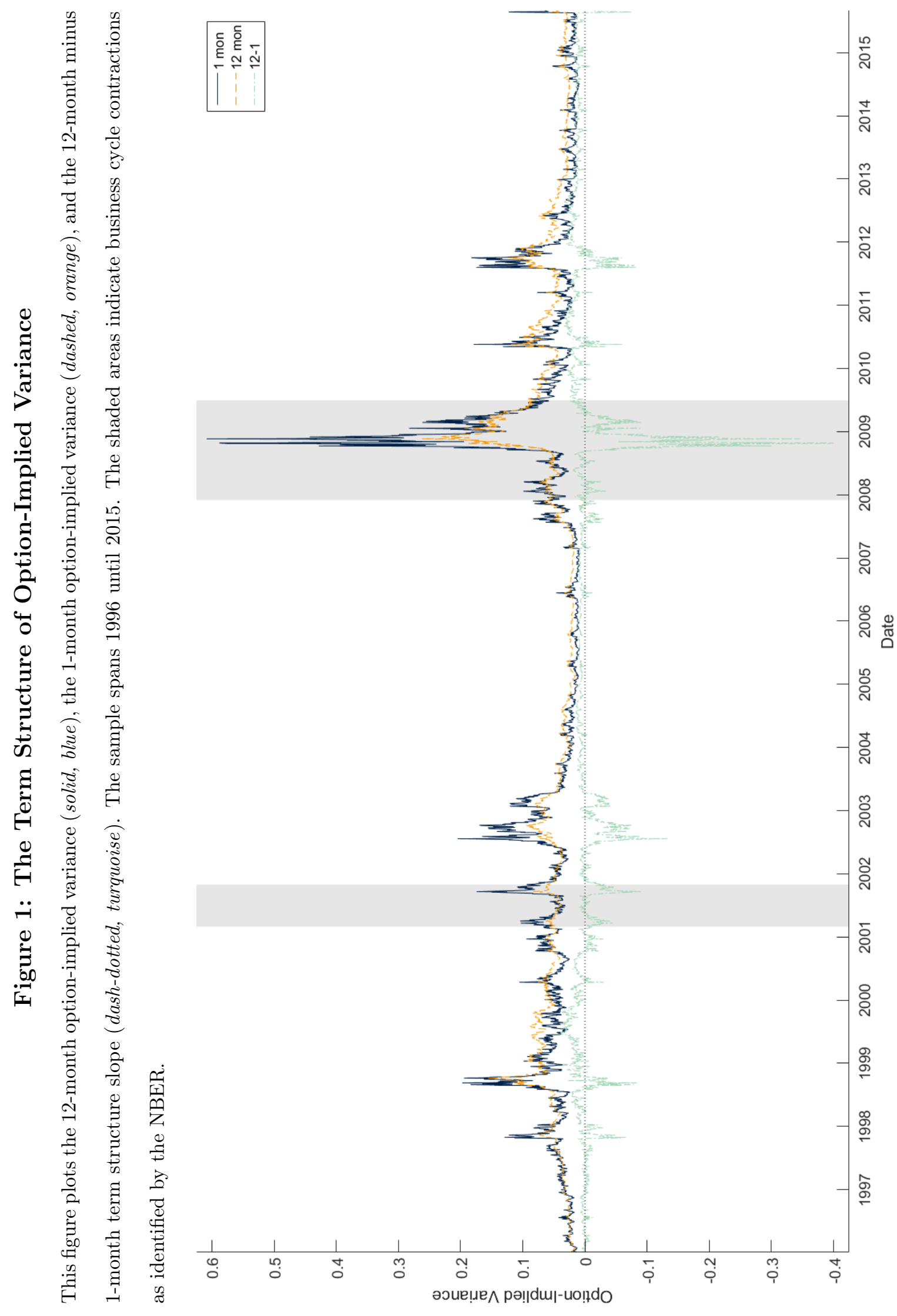




\section{Figure 2: The Time Series of Average Idiosyncratic Variance Term Premia}

This figure plots the average idiosyncratic variance term premium for the S\&P 500 stocks for the 12-month minus 1-month specification. The sample spans 1996 until 2015. The shaded areas indicate business cycle contractions as identified by the NBER.

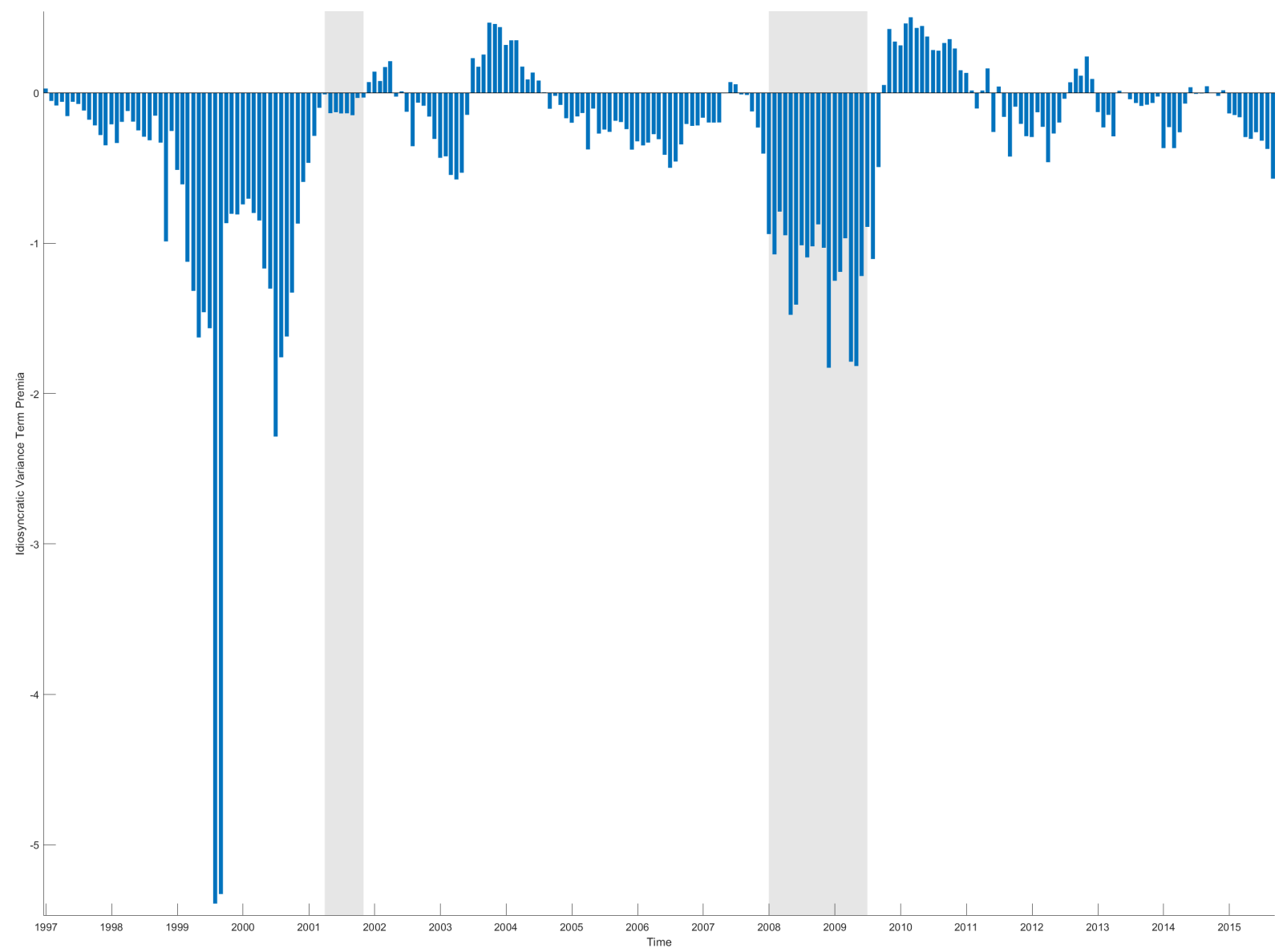




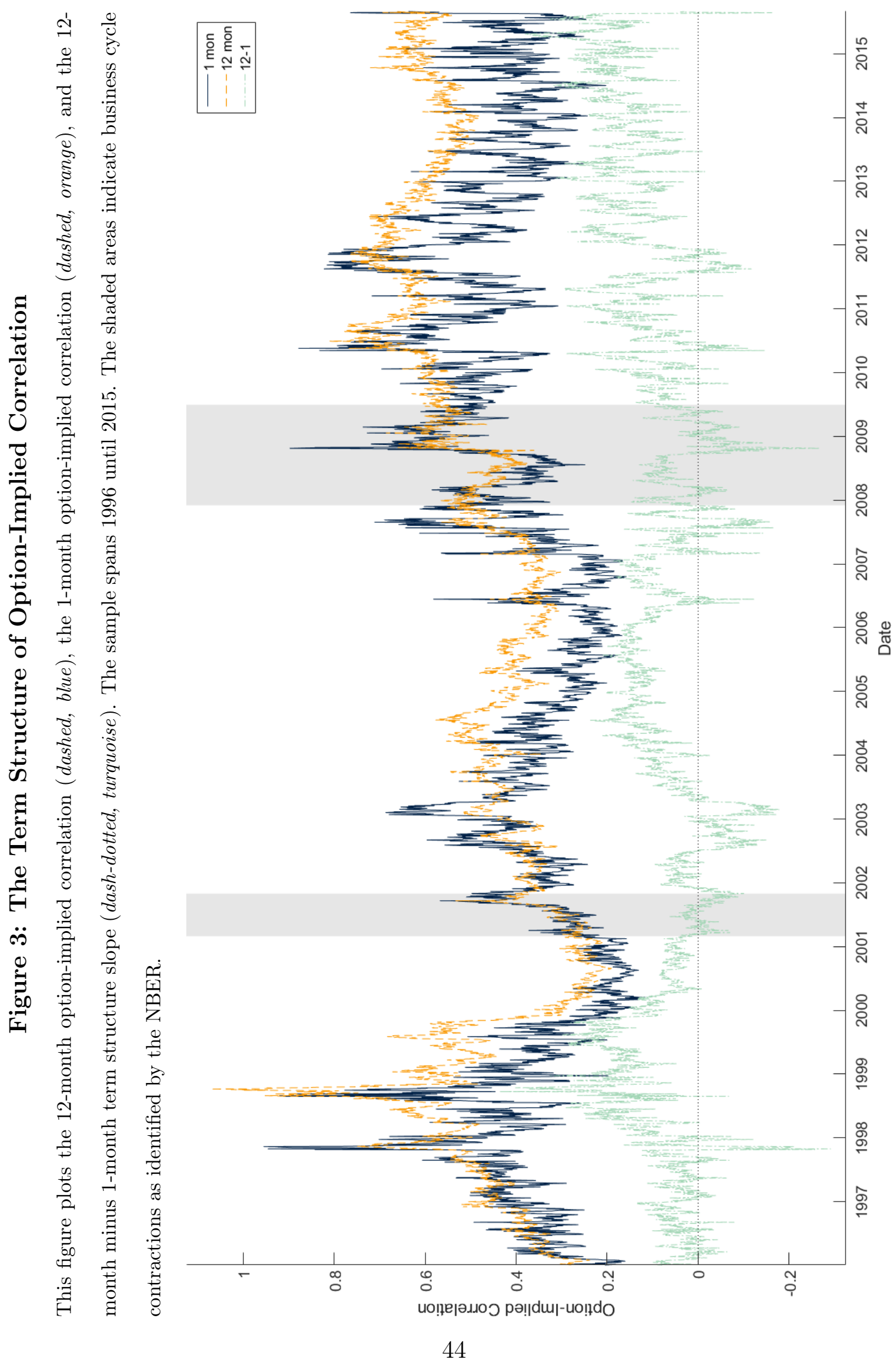




\section{Table 1: Summary Statistics}

This table presents summary statistics on the (annualized) option-implied variance of the market (Panel A) and individual stocks (Panel B) of different maturities, as well as summary statistics on the optionimplied beta (Panel C) idiosyncratic variance (Panel D), and correlation (Panel E). We report the results for maturities of 1, 3,6,9, and 12 months. Mean and Median are the overall average and median of the estimates over the entire sample period. Std. and $A R(1)$ present further summary statistics on the (average) standard deviations and first-order autocorrelations, while Skew and Kurt denote the (average) skewness and kurtosis, respectively. For individual stocks, we present cross-sectional averages of the firms' time-series statistics. In case of $\mathrm{Mean}_{v w}$, we present the time-series average of the value-weighted crosssectional average.

Panel A. Market Option-Implied Variance

\begin{tabular}{ccccccc}
\hline \hline Horizon & Mean & Median & Std. & AR(1) & Skew & Kurt \\
\hline 1 month & 0.046 & 0.035 & 0.041 & 0.789 & 3.27 & 17.8 \\
3 months & 0.047 & 0.039 & 0.035 & 0.842 & 2.69 & 13.0 \\
6 months & 0.048 & 0.041 & 0.030 & 0.878 & 2.29 & 10.4 \\
9 months & 0.049 & 0.042 & 0.028 & 0.894 & 2.11 & 9.30 \\
12 months & 0.049 & 0.044 & 0.027 & 0.903 & 2.00 & 8.76 \\
\hline \hline
\end{tabular}

Panel B. Stock Option-Implied Variance

\begin{tabular}{cccccccc}
\hline \hline Horizon & Mean & Mean $_{v w}$ & Median & Std. & AR(1) & Skew & Kurt \\
\hline 1 month & 0.166 & 0.116 & 0.097 & 0.153 & 0.772 & 2.64 & 13.9 \\
3 months & 0.156 & 0.112 & 0.093 & 0.132 & 0.856 & 2.43 & 12.3 \\
6 months & 0.149 & 0.110 & 0.092 & 0.118 & 0.882 & 2.26 & 11.1 \\
9 months & 0.147 & 0.109 & 0.093 & 0.111 & 0.889 & 2.13 & 10.1 \\
12 months & 0.145 & 0.109 & 0.094 & 0.103 & 0.898 & 2.06 & 9.78 \\
\hline \hline
\end{tabular}

\section{Panel C. Beta}

\begin{tabular}{cccccccc}
\hline \hline Horizon & Mean & Mean $n_{v w}$ & Median & Std. & AR(1) & Skew & Kurt \\
\hline 1 month & 1.076 & 0.975 & 1.024 & 0.277 & 0.738 & 0.47 & 4.70 \\
3 months & 1.071 & 0.991 & 1.018 & 0.239 & 0.842 & 0.32 & 4.16 \\
6 months & 1.070 & 0.993 & 1.023 & 0.221 & 0.869 & 0.30 & 4.10 \\
9 months & 1.067 & 0.992 & 1.019 & 0.214 & 0.872 & 0.31 & 4.08 \\
12 months & 1.061 & 0.993 & 1.016 & 0.205 & 0.875 & 0.29 & 4.00 \\
\hline \hline
\end{tabular}


Table 1: Summary Statistics (continued)

Panel D. Idiosyncratic Variance

\begin{tabular}{cccccccc}
\hline \hline Horizon & Mean & Mean $_{v w}$ & Median & Std. & AR(1) & Skew & Kurt \\
\hline 1 month & 0.104 & 0.064 & 0.054 & 0.098 & 0.797 & 2.41 & 11.8 \\
3 months & 0.094 & 0.060 & 0.050 & 0.085 & 0.873 & 2.36 & 11.4 \\
6 months & 0.087 & 0.057 & 0.046 & 0.078 & 0.895 & 2.31 & 10.9 \\
9 months & 0.085 & 0.056 & 0.045 & 0.074 & 0.902 & 2.20 & 10.0 \\
12 months & 0.083 & 0.055 & 0.046 & 0.068 & 0.909 & 2.12 & 9.50 \\
\hline \hline
\end{tabular}

Panel E. Option-Implied Correlation

\begin{tabular}{ccccccc}
\hline \hline Horizon & Mean & Median & Std. & AR(1) & Skew & Kurt \\
\hline 1 month & 0.418 & 0.403 & 0.138 & 0.744 & 0.49 & 3.05 \\
3 months & 0.447 & 0.449 & 0.128 & 0.814 & 0.32 & 3.73 \\
6 months & 0.476 & 0.480 & 0.123 & 0.886 & 0.03 & 3.06 \\
9 months & 0.487 & 0.500 & 0.123 & 0.912 & 0.01 & 2.86 \\
12 months & 0.490 & 0.493 & 0.120 & 0.915 & 0.03 & 2.85 \\
\hline \hline
\end{tabular}




\section{Table 2: Expectations Hypothesis Test: Option-Implied Variance}

This table reports the results of the expectations hypothesis tests for the model-free option-implied variance. In Panel A, we present the results for the S\&P 500 market index and Panel B shows the aggregated results for the individual stocks included in the S\&P 500. The regression equation is $\frac{1}{k} \sum_{i=0}^{k-1}\left(\sigma_{j, i m,(i+1) m}^{2}-\sigma_{j, 0, m}^{2}\right)=a_{j}+b_{j}\left(\sigma_{j, 0, k m}^{2}-\sigma_{j, 0, m}^{2}\right)+\nu_{j, k m}$. In each column, the first number denotes the long horizon ( $k$ times $m$ ) and the second number denotes the short horizon $(m)$ (e.g., 12,1 means we have $k m=12$ and $m=1$ month(s)). The pure expectations hypothesis posits that the constant $a$ is zero and that the slope $b$ is one while the general expectations hypothesis requires only the latter. We test the individual hypotheses with $t$-tests and the joint hypothesis with a Wald test. All tests employ Newey \& West (1987) standard errors (s.e.) with $\mathrm{km}$ lags. We also present the results of a joint test of the expectations hypothesis along with bootstrapped p-values. In Panel B, we present the results of a panel regression using the two-way clustered standard errors of Cameron et al. (2011). *, ${ }^{* *}$, and ${ }^{* * *}$ indicate significance at the $10 \%, 5 \%$, and $1 \%$ level, respectively.

\section{Panel A. Market}

\begin{tabular}{ccccccccc}
\hline \hline & $\mathbf{1 2 , 1}$ & $\mathbf{1 2 , 3}$ & $\mathbf{1 2 , 6}$ & $\mathbf{9 , 1}$ & $\mathbf{9 , 3}$ & $\mathbf{6 , 1}$ & $\mathbf{6 , 3}$ & $\mathbf{3 , 1}$ \\
\hline Const. & -0.003 & -0.002 & -0.001 & -0.003 & -0.002 & -0.002 & -0.001 & -0.001 \\
(s.e.) & $(0.004)$ & $(0.003)$ & $(0.002)$ & $(0.004)$ & $(0.003)$ & $(0.003)$ & $(0.002)$ & $(0.002)$ \\
Slope & 1.042 & 1.060 & 1.198 & 0.981 & 0.964 & 0.873 & 0.862 & 0.745 \\
(s.e.) & $(0.139)$ & $(0.208)$ & $(0.347)$ & $(0.123)$ & $(0.179)$ & $(0.142)$ & $(0.179)$ & $(0.230)$ \\
adj. R ${ }^{2}$ & 0.38 & 0.26 & 0.13 & 0.32 & 0.20 & 0.24 & 0.15 & 0.10 \\
Wald & 0.63 & 0.53 & 0.75 & 0.53 & 0.43 & 1.99 & 1.21 & 3.15 \\
p-value & {$[0.73]$} & {$[0.77]$} & {$[0.69]$} & {$[0.77]$} & {$[0.81]$} & {$[0.37]$} & {$[0.55]$} & {$[0.21]$} \\
\hline Joint & Pure & General & & & & & & \\
\hline Wald & 22.1 & 6.23 & & & & & & \\
p-value & {$[0.59]$} & {$[0.54]$} & & & & & & \\
\hline \hline
\end{tabular}

Panel B. Stocks

\begin{tabular}{ccccccccc}
\hline \hline & $\mathbf{1 2 , 1}$ & $\mathbf{1 2 , 3}$ & $\mathbf{1 2 , 6}$ & $\mathbf{9 , 1}$ & $\mathbf{9 , 3}$ & $\mathbf{6 , 1}$ & $\mathbf{6 , 3}$ & $\mathbf{3 , 1}$ \\
\hline Const. & $0.012^{* * *}$ & $0.006^{*}$ & 0.002 & $0.012^{* * *}$ & $0.005^{*}$ & $0.009^{* *}$ & 0.003 & $0.005^{*}$ \\
(s.e.) & $(0.005)$ & $(0.003)$ & $(0.003)$ & $(0.004)$ & $(0.003)$ & $(0.004)$ & $(0.002)$ & $(0.003)$ \\
Slope & 0.909 & 0.890 & $0.751^{* *}$ & 0.881 & $0.838 *$ & $0.754^{* * *}$ & $0.640^{* * *}$ & $0.620^{* * *}$ \\
(s.e.) & $(0.069)$ & $(0.088)$ & $(0.110)$ & $(0.078)$ & $(0.089)$ & $(0.078)$ & $(0.060)$ & $(0.065)$ \\
adj. R & 0.34 & 0.21 & 0.11 & 0.29 & 0.16 & 0.23 & 0.11 & 0.17 \\
Wald & {$[0.02]^{* *}$} & {$[0.18]$} & {$[0.07]^{*}$} & {$[0.02]^{* *}$} & {$[0.09]^{*}$} & {$[0.00]^{* * *}$} & {$[0.00]^{* * *}$} & {$[0.00]^{* * *}$} \\
\hline \hline
\end{tabular}




\section{Table 3: Stock Characteristics}

This table reports the average stock characteristics separately for stocks for which we can reject the pure expectations hypothesis in the term structure of option-implied variance and for those for which we cannot reject the pure expectations hypothesis. We present the results for different maturity combinations. In each column, the first number denotes the long horizon ( $k$ times $m$ ) and the second number denotes the short horizon $(m)$ (e.g., 12,1 means we have $k m=12$ and $m=1 \operatorname{month}(\mathrm{s})$ ). $\mathrm{IV}_{s t}$ and $\mathrm{IV}_{l t}$ denote the average option-implied variance for the respective short and long horizons. Weight is the average market capitalization share of the stocks relative to the total market share of stocks in our sample and Volume is the average daily options volume of the stocks in the respective groups.

\begin{tabular}{cccccccccc}
\hline \hline & & $\mathbf{1 2 , 1}$ & $\mathbf{1 2 , 3}$ & $\mathbf{1 2 , 6}$ & $\mathbf{9 , 1}$ & $\mathbf{9 , 3}$ & $\mathbf{6 , 1}$ & $\mathbf{6 , 3}$ & $\mathbf{3 , 1}$ \\
\hline \multirow{2}{*}{ rej. Stocks } & IV st & 0.19 & 0.17 & 0.16 & 0.19 & 0.18 & 0.17 & 0.17 & 0.16 \\
& $I V_{\text {lt }}$ & 0.16 & 0.16 & 0.15 & 0.16 & 0.17 & 0.15 & 0.16 & 0.15 \\
& Weight & 0.0013 & 0.0015 & 0.0013 & 0.0012 & 0.0013 & 0.0012 & 0.0011 & 0.0014 \\
& Volume & 4412 & 4700 & 3589 & 3780 & 4200 & 3081 & 3150 & 3399 \\
\hline \multirow{2}{*}{ non-rej. Stocks } & IV st & 0.16 & 0.15 & 0.14 & 0.16 & 0.15 & 0.16 & 0.15 & 0.18 \\
& IVlt & 0.14 & 0.14 & 0.14 & 0.14 & 0.14 & 0.15 & 0.15 & 0.17 \\
& Weight & 0.0022 & 0.0020 & 0.0020 & 0.0021 & 0.0020 & 0.0022 & 0.0021 & 0.0024 \\
& Volume & 6117 & 5551 & 5887 & 6164 & 5611 & 6863 & 6212 & 8069 \\
\hline \hline
\end{tabular}




\section{Table 4: Variance Term Premia}

This table reports the average returns to a strategy that takes a long position in the long-term optionimplied variance and rolls over short positions in the short-term option-implied variance. In Panel A, we present the results for the S\&P 500 market index and Panel B shows the aggregated results for the individual stocks included in the S\&P 500. The return is $\frac{\sigma_{j, 0, k m}^{2}-\frac{1}{k} \sum_{i=0}^{k-1} \sigma_{j, i m,(i+1) m}^{2}}{\sigma_{j, 0, k m}^{2}}$. In each column, the first number denotes the long horizon ( $k$ times $m$ ) and the second number denotes the short horizon $(m)$ (e.g., 12,1 means we have $k m=12$ and $m=1$ month(s)). In parentheses, we present Newey \& West (1987) standard errors (s.e.) with $\mathrm{km}$ lags. We also present the results of a joint test of that the returns of all maturity specifications are jointly zero along with bootstrapped p-values.In Panel B, we present the results of a panel regression on a constant using the two-way clustered standard errors of Cameron et al. (2011). ${ }^{*}{ }^{* *}$, and ${ }^{* * *}$ indicate significance at the $10 \%, 5 \%$, and $1 \%$ level, respectively.

Panel A. Market

\begin{tabular}{ccccccccc}
\hline \hline & $\mathbf{1 2 , 1}$ & $\mathbf{1 2 , 3}$ & $\mathbf{1 2 , 6}$ & $\mathbf{9 , 1}$ & $\mathbf{9 , 3}$ & $\mathbf{6 , 1}$ & $\mathbf{6 , 3}$ & $\mathbf{3 , 1}$ \\
\hline avg. Ret. & 0.011 & 0.001 & -0.011 & 0.010 & 0.003 & 0.016 & 0.012 & 0.004 \\
(s.e.) & $(0.093)$ & $(0.072)$ & $(0.043)$ & $(0.077)$ & $(0.055)$ & $(0.058)$ & $(0.033)$ & $(0.030)$ \\
\hline Joint & & & & & & & & \\
\cline { 1 - 2 } Wald & 1.08 & & & & & & & \\
p-value & {$[0.95]$} & & & & & & & \\
\hline \hline
\end{tabular}

Panel B. Stocks

\begin{tabular}{ccccccccc}
\hline \hline \multicolumn{12}{c}{$\mathbf{1}$} & $\mathbf{1 2 , 3}$ & $\mathbf{1 2 , 6}$ & $\mathbf{9 , 1}$ & $\mathbf{9 , 3}$ & $\mathbf{6 , 1}$ & $\mathbf{6 , 3}$ & $\mathbf{3 , 1}$ \\
\hline avg. Ret. & $-0.177^{* * *}$ & $-0.099^{* * *}$ & $-0.049^{* * *}$ & $-0.162^{* * *}$ & $-0.082^{* * *}$ & $-0.138^{* * *}$ & $-0.053^{* * *}$ & $-0.090^{* * *}$ \\
(s.e.) & $(0.032)$ & $(0.024)$ & $(0.018)$ & $(0.028)$ & $(0.021)$ & $(0.023)$ & $(0.014)$ & $(0.015)$ \\
\hline \hline
\end{tabular}




\section{Table 5: Expectations Hypothesis Test: Systematic Risk}

This table reports the results of the expectations hypothesis tests for systematic risk. We show the aggregated results for the individual stocks included in the S\&P 500. The regression equation is $\frac{1}{k} \sum_{i=0}^{k-1}\left(\beta_{j, i m,(i+1) m}^{2} \sigma_{M, i m,(i+1) m}^{2}-\beta_{j, 0, m}^{2} \sigma_{M, 0, m}^{2}\right)+\hat{\Delta}_{\beta \sigma}+\hat{\Delta}_{\beta r}+\hat{\Delta}_{\epsilon}=a_{j}+$ $b_{j}\left(\beta_{j, 0, k m}^{2} \sigma_{M, 0, k m}^{2}-\beta_{j, 0, m}^{2} \sigma_{M, 0, m}^{2}\right)+\nu_{j, k m}$. In each column, the first number denotes the long horizon ( $k$ times $m$ ) and the second number denotes the short horizon $(m)$ (e.g., 12,1 means we have $k m=12$ and $m=1$ month(s)). The pure expectations hypothesis posits that the constant $a$ is zero and that the slope $b$ is one while the general expectations hypothesis requires only the latter. We test the individual hypotheses with $t$-tests and the joint hypothesis with a Wald test. All tests employ a panel regression approach using the two-way clustered standard errors of Cameron et al. (2011). ${ }^{*},{ }^{* *}$, and ${ }^{* * *}$ indicate significance at the $10 \%, 5 \%$, and $1 \%$ level, respectively.

\begin{tabular}{ccccccccc}
\hline \hline & $\mathbf{1 2 , 1}$ & $\mathbf{1 2 , 3}$ & $\mathbf{1 2 , 6}$ & $\mathbf{9 , 1}$ & $\mathbf{9 , 3}$ & $\mathbf{6 , 1}$ & $\mathbf{6 , 3}$ & $\mathbf{3 , 1}$ \\
\hline Const. & $0.012^{* *}$ & $0.007^{*}$ & 0.002 & $0.012^{* *}$ & $0.006^{*}$ & $0.011^{* * *}$ & $0.005^{* *}$ & $0.007^{* *}$ \\
(s.e.) & $(0.005)$ & $(0.004)$ & $(0.003)$ & $(0.005)$ & $(0.003)$ & $(0.004)$ & $(0.002)$ & $(0.003)$ \\
Slope & 1.149 & 1.286 & 0.914 & 1.109 & 1.120 & 0.916 & 0.917 & 0.741 \\
(s.e.) & $(0.164)$ & $(0.228)$ & $(0.372)$ & $(0.164)$ & $(0.228)$ & $(0.171)$ & $(0.212)$ & $(0.237)$ \\
adj. R ${ }^{2}$ & 0.20 & 0.13 & 0.03 & 0.18 & 0.09 & 0.13 & 0.06 & 0.07 \\
Wald & {$[0.01]^{* * *}$} & {$[0.02]^{* *}$} & {$[0.67]$} & {$[0.01]^{* *}$} & {$[0.08]^{*}$} & {$[0.03]^{* *}$} & {$[0.09]^{*}$} & {$[0.07]^{*}$} \\
\hline \hline
\end{tabular}




\section{Table 6: Expectations Hypothesis Test: Idiosyncratic Variance}

This table reports the results of the expectations hypothesis tests for idiosyncratic variance. We show the aggregated results for the individual stocks included in the S\&P 500. The regression equation is $\frac{1}{k} \sum_{i=0}^{k-1}\left(\sigma_{\epsilon, j, i m,(i+1) m}^{2}-\sigma_{\epsilon, j, 0, m}^{2}\right)=a_{j}+b_{j}\left(\sigma_{\epsilon, j, 0, k m}^{2}-\sigma_{\epsilon, j, 0, m}^{2}\right)+\nu_{j, k m}$. In each column, the first number denotes the long horizon ( $k$ times $m$ ) and the second number denotes the short horizon $(m)$ (e.g., 12,1 means we have $k m=12$ and $m=1$ month(s)). The pure expectations hypothesis posits that the constant $a$ is zero and that the slope $b$ is one while the general expectations hypothesis requires only the latter. We test the individual hypotheses with $t$-tests and the joint hypothesis with a Wald test. All tests employ a panel regression approach using the two-way clustered standard errors of Cameron et al. (2011). * ${ }^{* *}$, and $^{* * *}$ indicate significance at the $10 \%, 5 \%$, and $1 \%$ level, respectively.

\begin{tabular}{ccccccccc}
\hline \hline & $\mathbf{1 2 , 1}$ & $\mathbf{1 2 , 3}$ & $\mathbf{1 2 , 6}$ & $\mathbf{9 , 1}$ & $\mathbf{9 , 3}$ & $\mathbf{6 , 1}$ & $\mathbf{6 , 3}$ & $\mathbf{3 , 1}$ \\
\hline Const. & $0.008^{* * *}$ & $0.005^{* *}$ & 0.002 & $0.008^{* * *}$ & $0.004^{* *}$ & $0.006^{* * *}$ & $0.002^{* *}$ & $0.004^{* *}$ \\
(s.e.) & $(0.002)$ & $(0.002)$ & $(0.001)$ & $(0.002)$ & $(0.002)$ & $(0.002)$ & $(0.001)$ & $(0.001)$ \\
Slope & $0.737^{* * *}$ & $0.724^{* * *}$ & $0.651^{* * *}$ & $0.696^{* * *}$ & $0.629^{* * *}$ & $0.601^{* * *}$ & $0.455^{* * *}$ & $0.548^{* * *}$ \\
(s.e.) & $(0.060)$ & $(0.088)$ & $(0.103)$ & $(0.069)$ & $(0.083)$ & $(0.078)$ & $(0.091)$ & $(0.076)$ \\
adj. R ${ }^{2}$ & 0.23 & 0.15 & 0.09 & 0.18 & 0.09 & 0.15 & 0.04 & 0.12 \\
Wald & {$[0.00]^{* * *}$} & {$[0.00]^{* * *}$} & {$[0.00]^{* * *}$} & {$[0.00]^{* * *}$} & {$[0.00]^{* * *}$} & {$[0.00]^{* * *}$} & {$[0.00]^{* * *}$} & {$[0.00]^{* * *}$} \\
\hline \hline
\end{tabular}




\section{Table 7: Idiosyncratic Variance Term Premia}

This table reports the average returns to a strategy that takes a long position in the long-term optionimplied idiosyncratic variance and rolls over short positions in the short-term option-implied idiosyncratic variance. We show the aggregated results for the individual stocks included in the S\&P 500. The return

is $\frac{\sigma_{\epsilon, j, 0, k m}^{2}-\frac{1}{k} \sum_{i=0}^{k-1} \sigma_{\epsilon, j, i m,(i+1) m}^{2}}{\sigma_{\epsilon, j, 0, k m}^{2}}$. In each column, the first number denotes the long horizon ( $k$ times $m$ ) and the second number denotes the short horizon $(m$ ) (e.g., 12,1 means we have $k m=12$ and $m=1$ month(s)). We present the results of a panel regression on a constant using the two-way clustered standard errors of Cameron et al. (2011). ${ }^{*},{ }^{* *}$, and ${ }^{* * *}$ indicate significance at the $10 \%, 5 \%$, and $1 \%$ level, respectively.

\begin{tabular}{ccccccccc}
\hline \hline & $\mathbf{1 2 , 1}$ & $\mathbf{1 2 , 3}$ & $\mathbf{1 2 , 6}$ & $\mathbf{9 , 1}$ & $\mathbf{9 , 3}$ & $\mathbf{6 , 1}$ & $\mathbf{6 , 3}$ & $\mathbf{3 , 1}$ \\
\hline avg. Ret. & $-0.377^{* * *}$ & $-0.236^{* * *}$ & $-0.119^{* * *}$ & $-0.323^{* * *}$ & $-0.211^{* * *}$ & $-0.262^{* * *}$ & $-0.130^{* * *}$ & $-0.162^{*}$ \\
(s.e.) & $(0.067)$ & $(0.053)$ & $(0.042)$ & $(0.057)$ & $(0.039)$ & $(0.089)$ & $(0.044)$ & $(0.093)$ \\
\hline \hline
\end{tabular}




\section{Table 8: Explaining Idiosyncratic Variance Term Premia}

This table reports the results of a panel regression of idiosyncratic variance term premia on different stock and aggregate time-series characteristics. All characteristics are observed at the same time with the idiosyncratic variance for the long horizon, i.e., at the beginning of the trading period for the idiosyncratic variance term premia. "log(Size)" and "log(BtM)" are the natural logarithms of the stocks' market capitalization and book-to-market ratio, respectively. "Momentum" denotes the cumulative return of the stocks during the months $t-12$ until $t-1$ and "Opt. Volume" is the average daily options volume during the past month. "DEF" is the default spread (average yield of BAA minus that of AAA rated corporate bonds) and "TERM" is the term spread (yield of long-term government bonds minus that on t-bills). In each column, the first number denotes the long horizon ( $k$ times $m$ ) and the second number denotes the short horizon $(m)$ (e.g., 12,1 means we have $k m=12$ and $m=1 \operatorname{month}(\mathrm{s})$ ). We use the two-way clustered standard errors of Cameron et al. (2011). * , **, and ${ }^{* * *}$ indicate significance at the 10\%, 5\%, and $1 \%$ level, respectively.

\begin{tabular}{ccccccccc}
\hline \hline & $\mathbf{1 2 , 1}$ & $\mathbf{1 2 , 3}$ & $\mathbf{1 2 , 6}$ & $\mathbf{9 , 1}$ & $\mathbf{9 , 3}$ & $\mathbf{6 , 1}$ & $\mathbf{6 , 3}$ & $\mathbf{3 , 1}$ \\
\hline Intercept & $-1.444^{* * *}$ & $-0.529^{* *}$ & -0.161 & $-1.303^{* * *}$ & $-0.380^{*}$ & $-1.251^{* * *}$ & $-0.306^{* *}$ & $-0.702^{* * *}$ \\
(s.e.) & $(0.416)$ & $(0.253)$ & $(0.176)$ & $(0.405)$ & $(0.212)$ & $(0.422)$ & $(0.150)$ & $(0.241)$ \\
$\log$ (Size) & 0.025 & -0.005 & -0.009 & 0.027 & -0.005 & $0.035^{*}$ & 0.001 & 0.004 \\
(s.e.) & $(0.021)$ & $(0.013)$ & $(0.009)$ & $(0.019)$ & $(0.010)$ & $(0.019)$ & $(0.008)$ & $(0.010)$ \\
$\log$ (BtM) & $-0.061^{* * *}$ & $-0.041^{* * *}$ & $-0.023^{* *}$ & $-0.045^{* *}$ & $-0.037^{* * *}$ & $-0.030^{* *}$ & $-0.027^{* * *}$ & -0.000 \\
(s.e.) & $(0.023)$ & $(0.015)$ & $(0.010)$ & $(0.018)$ & $(0.011)$ & $(0.012)$ & $(0.008)$ & $(0.032)$ \\
Momentum & 0.059 & 0.040 & 0.030 & 0.044 & 0.021 & 0.017 & 0.002 & 0.154 \\
(s.e.) & $(0.045)$ & $(0.034)$ & $(0.024)$ & $(0.038)$ & $(0.026)$ & $(0.028)$ & $(0.016)$ & $(0.143)$ \\
Opt. Volume & -0.000 & -0.000 & -0.000 & -0.000 & 0.000 & -0.000 & -0.000 & 0.000 \\
(s.e.) & $(0.000)$ & $(0.000)$ & $(0.000)$ & $(0.000)$ & $(0.000)$ & $(0.000)$ & $(0.000)$ & $(0.000)$ \\
DEF & $24.23^{* * *}$ & $12.48^{* * *}$ & $5.920^{*}$ & $23.95^{* * *}$ & $11.23^{* * *}$ & $19.90^{* * *}$ & $7.585^{* * *}$ & $20.12^{*}$ \\
(s.e.) & $(5.098)$ & $(4.424)$ & $(3.488)$ & $(4.693)$ & $(3.624)$ & $(4.234)$ & $(2.496)$ & $(10.78)$ \\
TERM & $15.69^{* * *}$ & $8.897^{* * *}$ & $4.573^{* * *}$ & $10.39^{* * *}$ & $5.106^{* * *}$ & $7.570^{* *}$ & $2.552^{* *}$ & 8.576 \\
(s.e.) & $(3.505)$ & $(2.385)$ & $(1.634)$ & $(3.059)$ & $(1.893)$ & $(3.007)$ & $(1.162)$ & $(5.777)$ \\
adj. R & 0.036 & 0.024 & 0.013 & 0.026 & 0.013 & 0.012 & 0.008 & 0.000 \\
Wald & $59.26^{* * *}$ & $33.44^{* * *}$ & $19.01^{* * *}$ & $67.85^{* * *}$ & $38.09^{* * *}$ & $45.93^{* * *}$ & $29.86^{* * *}$ & $45.49^{* * *}$ \\
p-value & {$[0.000]$} & {$[0.000]$} & {$[0.004]$} & {$[0.000]$} & {$[0.000]$} & {$[0.000]$} & {$[0.000]$} & {$[0.000]$} \\
\hline \hline
\end{tabular}




\section{Table 9: Expectations Hypothesis Test: Forward Unbiasedness}

This table reports the results of the expectations hypothesis tests for the model-free option-implied variance. In Panel A, we present the results for the S\&P 500 market index and Panel B shows the aggregated results for the individual stocks included in the S\&P 500. The regression equation is $\sigma_{j, m, k m}^{2}-$

$\sigma_{j, 0, m}^{2}=a_{j}+b_{j}\left(f_{j, 0, m, k m}^{2}-\sigma_{j, 0, m}^{2}\right)+\nu_{j, k m}$, with $f_{j, 0, m, k m}^{2}=\sigma_{j, 0, k m}^{2}+\frac{1}{k-1}\left(\sigma_{j, 0, k m}^{2}-\sigma_{j, 0, m}^{2}\right)$. In each column, the first number denotes the long horizon ( $k$ times $m$ ) and the second number denotes the short horizon $(m)$ (e.g., 12,3 means we have $k m=12$ and $m=3$ month(s)). The pure expectations hypothesis posits that the constant $a$ is zero and that the slope $b$ is one while the general expectations hypothesis requires only the latter. We test the individual hypotheses with $t$-tests and the joint hypothesis with a Wald test. All tests employ Newey \& West (1987) standard errors (s.e.) with $\mathrm{km}$ lags. We also present the results of a joint test of the expectations hypothesis along with bootstrapped p-values.In Panel B, we present the results of a panel regression on a constant using the two-way clustered standard errors of Cameron et al. (2011). ${ }^{*},{ }^{* *}$, and ${ }^{* * *}$ indicate significance at the $10 \%, 5 \%$, and $1 \%$ level, respectively.

Panel A. Market

\begin{tabular}{cccccccc}
\hline \hline & $\mathbf{1 2 , 3}$ & $\mathbf{1 2 , 6}$ & $\mathbf{1 2 , 9}$ & $\mathbf{9 , 3}$ & $\mathbf{9 , 6}$ & $\mathbf{6 , 3}$ & $\mathbf{3 , 1}$ \\
\hline Const. & -0.001 & -0.003 & -0.005 & -0.001 & -0.003 & -0.002 & 0.000 \\
(s.e.) & $(0.002)$ & $(0.004)$ & $(0.006)$ & $(0.003)$ & $(0.005)$ & $(0.003)$ & $(0.002)$ \\
Slope & 1.003 & 1.198 & 1.389 & 0.945 & 1.051 & 0.862 & $0.582^{*}$ \\
(s.e.) & $(0.112)$ & $(0.347)$ & $(0.767)$ & $(0.135)$ & $(0.375)$ & $(0.179)$ & $(0.223)$ \\
adj. R & 0.36 & 0.13 & 0.07 & 0.27 & 0.07 & 0.15 & 0.10 \\
Wald & 0.34 & 0.75 & 0.66 & 0.51 & 0.37 & 1.21 & $9.00^{* *}$ \\
p-value & {$[0.85]$} & {$[0.69]$} & {$[0.72]$} & {$[0.78]$} & {$[0.83]$} & {$[0.55]$} & {$[0.01]$} \\
\hline Joint & Pure & General & & & & & \\
\hline Wald & 14.8 & 5.49 & & & & & \\
p-value & {$[0.77]$} & {$[0.67]$} & & & & & \\
\hline \hline
\end{tabular}


Table 9: Expectations Hypothesis Test: Forward Unbiasedness (continued)

Panel B. Stocks

\begin{tabular}{cccccccc}
\hline \hline & $\mathbf{1 2 , 3}$ & $\mathbf{1 2 , 6}$ & $\mathbf{1 2 , 9}$ & $\mathbf{9 , 3}$ & $\mathbf{9 , 6}$ & $\mathbf{6 , 3}$ & $\mathbf{3 , 1}$ \\
\hline Const. & 0.002 & 0.004 & 0.007 & 0.003 & 0.008 & 0.007 & 0.004 \\
(s.e.) & $(0.003)$ & $(0.005)$ & $(0.007)$ & $(0.004)$ & $(0.006)$ & $(0.005)$ & $(0.003)$ \\
Slope & $0.787^{* * *}$ & $0.751^{* *}$ & $0.493^{* * *}$ & $0.785^{* * *}$ & $0.768^{* *}$ & $0.640^{* * *}$ & $0.588^{* * *}$ \\
(s.e.) & $(0.054)$ & $(0.110)$ & $(0.083)$ & $(0.052)$ & $(0.102)$ & $(0.060)$ & $(0.058)$ \\
adj. R ${ }^{2}$ & 0.26 & 0.11 & 0.05 & 0.22 & 0.08 & 0.11 & 0.18 \\
Wald & {$[0.00]^{* * *}$} & {$[0.07]^{*}$} & {$[0.00]^{* * *}$} & {$[0.00]^{* * *}$} & {$[0.05]^{*}$} & {$[0.00]^{* * *}$} & {$[0.00]^{* * *}$} \\
\hline \hline
\end{tabular}

Panel C. Idiosyncratic Variance

\begin{tabular}{cccccccc}
\hline \hline & $\mathbf{1 2 , 3}$ & $\mathbf{1 2 , 6}$ & $\mathbf{1 2 , 9}$ & $\mathbf{9 , 3}$ & $\mathbf{9 , 6}$ & $\mathbf{6 , 3}$ & $\mathbf{3 , 1}$ \\
\hline Const. & 0.001 & 0.004 & $0.009^{* *}$ & 0.002 & $0.009^{* * *}$ & $0.005^{* *}$ & $0.005^{* * *}$ \\
(s.e.) & $(0.002)$ & $(0.003)$ & $(0.004)$ & $(0.002)$ & $(0.003)$ & $(0.002)$ & $(0.002)$ \\
Slope & $0.672^{* * *}$ & $0.647^{* * *}$ & $0.402^{* * *}$ & $0.667^{* * *}$ & $0.566^{* * *}$ & $0.466^{* * *}$ & $0.590^{* * *}$ \\
(s.e.) & $(0.053)$ & $(0.101)$ & $(0.079)$ & $(0.059)$ & $(0.095)$ & $(0.086)$ & $(0.057)$ \\
adj. R ${ }^{2}$ & 0.19 & 0.09 & 0.05 & 0.13 & 0.05 & 0.04 & 0.18 \\
Wald & {$[0.00]^{* * *}$} & {$[0.00]^{* * *}$} & {$[0.00]^{* * *}$} & {$[0.00]^{* * *}$} & {$[0.00]^{* * *}$} & {$[0.00]^{* * *}$} & {$[0.00]^{* * *}$} \\
\hline \hline
\end{tabular}




\section{Table 10: Expectations Hypothesis Test: Option-Implied Correlation}

This table reports the results of the expectations hypothesis tests for the option-implied correlation of the

stocks of the S\&P 500. The regression equation is $\frac{1}{k} \sum_{i=0}^{k-1}\left(\rho_{i m,(i+1) m} \frac{q_{i m,(i+1) m}^{*}}{q_{0, k m}^{*}}-\rho_{0, m}\right)+\hat{\Delta}_{Q V}+\hat{\Delta}_{p q}=$ $a+b\left(\rho_{0, k m}-\rho_{0, m}\right)+\nu_{k m}$. In each column, the first number denotes the long horizon ( $k$ times $\left.m\right)$ and the second number denotes the short horizon $(m)$ (e.g., 12,1 means we have $k m=12$ and $m=1$ month(s)). The pure expectations hypothesis posits that the constant $a$ is zero and that the slope $b$ is one while the general expectations hypothesis requires only the latter. We test the individual hypotheses with $t$-tests and the joint hypothesis with a Wald test. All tests employ Newey \& West (1987) standard errors (s.e.) with $\mathrm{km}$ lags. We also present the results of a joint test of the expectations hypothesis along with bootstrapped p-values. ${ }^{*},{ }^{* *}$, and ${ }^{* * *}$ indicate significance at the $10 \%, 5 \%$, and $1 \%$ level, respectively.

\begin{tabular}{ccccccccc}
\hline \hline & $\mathbf{1 2 , 1}$ & $\mathbf{1 2 , 3}$ & $\mathbf{1 2 , 6}$ & $\mathbf{9 , 1}$ & $\mathbf{9 , 3}$ & $\mathbf{6 , 1}$ & $\mathbf{6 , 3}$ & $\mathbf{3 , 1}$ \\
\hline Const. & 0.035 & 0.027 & 0.008 & 0.043 & 0.035 & 0.024 & 0.011 & 0.019 \\
(s.e.) & $(0.048)$ & $(0.034)$ & $(0.019)$ & $(0.039)$ & $(0.025)$ & $(0.027)$ & $(0.014)$ & $(0.018)$ \\
Slope & 0.626 & 0.504 & 0.704 & 0.631 & 0.470 & 0.689 & 0.673 & 0.499 \\
(s.e.) & $(0.292)$ & $(0.385)$ & $(0.571)$ & $(0.273)$ & $(0.369)$ & $(0.218)$ & $(0.349)$ & $(0.323)$ \\
adj. R & 0.04 & 0.02 & 0.01 & 0.04 & 0.01 & 0.05 & 0.03 & 0.02 \\
Wald & 1.65 & 1.68 & 0.37 & 2.00 & 2.66 & 2.08 & 1.05 & 2.51 \\
p-value & {$[0.44]$} & {$[0.43]$} & {$[0.83]$} & {$[0.37]$} & {$[0.26]$} & {$[0.35]$} & {$[0.59]$} & {$[0.28]$} \\
\hline Joint & Pure & General & & & & & & \\
\hline Wald & 35.2 & 30.0 & & & & & & \\
p-value & {$[0.91]$} & {$[0.22]$} & & & & & & \\
\hline \hline
\end{tabular}




\section{Table 11: Expectations Hypothesis Test: Option-Implied Variance - The Role of Jumps}

This table reports the results of the expectations hypothesis tests for the model-free option-implied variance. In Panel A, we present the results for the S\&P 500 market index and Panel B shows the aggregated results for the individual stocks included in the S\&P 500. The regression equation is $\frac{1}{k} \sum_{i=0}^{k-1}\left(\sigma_{j, i m,(i+1) m}^{2}-\sigma_{j, 0, m}^{2}\right)=a_{j}+b_{j}\left(\sigma_{j, 0, k m}^{2}-\sigma_{j, 0, m}^{2}\right)+\nu_{j, k m}$. In each column, the first number denotes the long horizon ( $k$ times $m$ ) and the second number denotes the short horizon $(m)$ (e.g., 12,1 means we have $k m=12$ and $m=1$ month(s)). The pure expectations hypothesis posits that the constant $a$ is zero and that the slope $b$ is one while the general expectations hypothesis requires only the latter. We test the individual hypotheses with $t$-tests and the joint hypothesis with a Wald test. All tests employ Newey \& West (1987) standard errors (s.e.) with $\mathrm{km}$ lags. We also present the results of a joint test of the expectations hypothesis along with bootstrapped p-values. In Panel B, we present the results of a panel regression on a constant using the two-way clustered standard errors of Cameron et al. (2011). *, ${ }^{* *}$, and ${ }^{* * *}$ indicate significance at the $10 \%, 5 \%$, and $1 \%$ level, respectively.

Panel A. Market

\begin{tabular}{ccccccccc}
\hline \hline & $\mathbf{1 2 , 1}$ & $\mathbf{1 2 , 3}$ & $\mathbf{1 2 , 6}$ & $\mathbf{9 , 1}$ & $\mathbf{9 , 3}$ & $\mathbf{6 , 1}$ & $\mathbf{6 , 3}$ & $\mathbf{3 , 1}$ \\
\hline Const. & -0.005 & -0.003 & -0.001 & -0.004 & -0.002 & -0.003 & -0.001 & -0.001 \\
(s.e.) & $(0.005)$ & $(0.004)$ & $(0.002)$ & $(0.004)$ & $(0.003)$ & $(0.003)$ & $(0.002)$ & $(0.002)$ \\
Slope & 0.973 & 0.947 & 0.880 & 0.931 & 0.887 & 0.844 & 0.834 & 0.706 \\
(s.e.) & $(0.184)$ & $(0.261)$ & $(0.402)$ & $(0.151)$ & $(0.210)$ & $(0.145)$ & $(0.188)$ & $(0.253)$ \\
adj. R & 0.30 & 0.19 & 0.06 & 0.26 & 0.15 & 0.20 & 0.12 & 0.08 \\
Wald & 1.06 & 0.78 & 0.59 & 1.23 & 0.96 & 2.93 & 1.64 & 4.39 \\
p-value & {$[0.59]$} & {$[0.68]$} & {$[0.75]$} & {$[0.54]$} & {$[0.62]$} & {$[0.23]$} & {$[0.44]$} & {$[0.11]$} \\
\hline Joint & Pure & General & & & & & & \\
\hline Wald & 56.5 & 13.8 & & & & & & \\
p-value & {$[0.50]$} & {$[0.42]$} & & & & & & \\
\hline \hline
\end{tabular}

Panel B. Stocks

\begin{tabular}{ccccccccc}
\hline \hline & $\mathbf{1 2 , 1}$ & $\mathbf{1 2 , 3}$ & $\mathbf{1 2 , 6}$ & $\mathbf{9 , 1}$ & $\mathbf{9 , 3}$ & $\mathbf{6 , 1}$ & $\mathbf{6 , 3}$ & $\mathbf{3 , 1}$ \\
\hline Const. & $0.009^{*}$ & 0.005 & 0.002 & $0.009^{*}$ & 0.004 & 0.007 & 0.003 & 0.004 \\
(s.e.) & $(0.005)$ & $(0.004)$ & $(0.003)$ & $(0.005)$ & $(0.004)$ & $(0.004)$ & $(0.003)$ & $(0.003)$ \\
Slope & $0.872^{* *}$ & $0.801^{* * *}$ & $0.610^{* * *}$ & $0.879^{*}$ & $0.737^{* * *}$ & $0.698^{* * *}$ & $0.545^{* * *}$ & $0.598^{* * *}$ \\
(s.e.) & $(0.054)$ & $(0.060)$ & $(0.074)$ & $(0.067)$ & $(0.086)$ & $(0.092)$ & $(0.095)$ & $(0.052)$ \\
adj. R & 0.37 & 0.26 & 0.14 & 0.30 & 0.18 & 0.22 & 0.11 & 0.18 \\
Wald & {$[0.03]^{* *}$} & {$[0.00]^{* * *}$} & {$[0.00]^{* * *}$} & {$[0.06]^{*}$} & {$[0.01]^{* * *}$} & {$[0.00]^{* * *}$} & {$[0.00]^{* * *}$} & {$[0.00]^{* * *}$} \\
\hline \hline
\end{tabular}




\section{Table 12: Expectations Hypothesis Test: Systematic Risk - The Role of Jumps}

This table reports the results of the expectations hypothesis tests for systematic risk. We show the aggregated results for the individual stocks included in the S\&P 500. The regression equation is $\frac{1}{k} \sum_{i=0}^{k-1}\left(\beta_{j, i m,(i+1) m}^{2} \sigma_{M, i m,(i+1) m}^{2}-\beta_{j, 0, m}^{2} \sigma_{M, 0, m}^{2}\right)+\hat{\Delta}_{\beta \sigma}+\hat{\Delta}_{\beta r}+\hat{\Delta}_{\epsilon}=a_{j}+$ $b_{j}\left(\beta_{j, 0, k m}^{2} \sigma_{M, 0, k m}^{2}-\beta_{j, 0, m}^{2} \sigma_{M, 0, m}^{2}\right)+\nu_{j, k m}$. In each column, the first number denotes the long horizon ( $k$ times $m$ ) and the second number denotes the short horizon $(m$ ) (e.g., 12,1 means we have $k m=12$ and $m=1$ month(s)). The pure expectations hypothesis posits that the constant $a$ is zero and that the slope $b$ is one while the general expectations hypothesis requires only the latter. We test the individual hypotheses with $t$-tests and the joint hypothesis with a Wald test. All tests employ a panel regression approach using the two-way clustered standard errors of Cameron et al. (2011). ${ }^{*},{ }^{* *}$, and ${ }^{* * *}$ indicate significance at the $10 \%, 5 \%$, and $1 \%$ level, respectively.

\begin{tabular}{ccccccccc}
\hline \hline & $\mathbf{1 2 , 1}$ & $\mathbf{1 2 , 3}$ & $\mathbf{1 2 , 6}$ & $\mathbf{9 , 1}$ & $\mathbf{9 , 3}$ & $\mathbf{6 , 1}$ & $\mathbf{6 , 3}$ & $\mathbf{3 , 1}$ \\
\hline Const. & 0.010 & 0.007 & 0.004 & 0.010 & 0.006 & 0.010 & 0.006 & 0.006 \\
(s.e.) & $(0.009)$ & $(0.007)$ & $(0.005)$ & $(0.009)$ & $(0.006)$ & $(0.008)$ & $(0.005)$ & $(0.006)$ \\
Slope & 1.044 & 0.947 & $0.367^{* * *}$ & 1.086 & 1.009 & 0.837 & 0.632 & $0.606^{*}$ \\
(s.e.) & $(0.136)$ & $(0.176)$ & $(0.221)$ & $(0.152)$ & $(0.199)$ & $(0.218)$ & $(0.272)$ & $(0.201)$ \\
adj. R & 0.20 & 0.11 & 0.03 & 0.18 & 0.10 & 0.11 & 0.04 & 0.05 \\
Wald & {$[0.00]^{* * *}$} & {$[0.00]^{* * *}$} & {$[0.00]^{* * *}$} & {$[0.00]^{* * *}$} & {$[0.00]^{* * *}$} & {$[0.00]^{* * *}$} & {$[0.00]^{* * *}$} & {$[0.00]^{* * *}$} \\
\hline \hline
\end{tabular}




\section{Table 13: Expectations Hypothesis Test: Idiosyncratic Variance - The Role of Jumps}

This table reports the results of the expectations hypothesis tests for idiosyncratic variance. We show the aggregated results for the individual stocks included in the S\&P 500. The regression equation is $\frac{1}{k} \sum_{i=0}^{k-1}\left(\sigma_{\epsilon, j, i m,(i+1) m}^{2}-\sigma_{\epsilon, j, 0, m}^{2}\right)=a_{j}+b_{j}\left(\sigma_{\epsilon, j, 0, k m}^{2}-\sigma_{\epsilon, j, 0, m}^{2}\right)+\nu_{j, k m}$. In each column, the first number denotes the long horizon ( $k$ times $m$ ) and the second number denotes the short horizon $(m)$ (e.g., 12,1 means we have $\mathrm{km}=12$ and $m=1 \operatorname{month}(\mathrm{s})$ ). The pure expectations hypothesis posits that the constant $a$ is zero and that the slope $b$ is one while the general expectations hypothesis requires only the latter. We test the individual hypotheses with $t$-tests and the joint hypothesis with a Wald test. All tests employ a panel regression approach using the two-way clustered standard errors of Cameron et al. (2011). ${ }^{*},{ }^{* *}$, and $^{* * *}$ indicate significance at the $10 \%, 5 \%$, and $1 \%$ level, respectively.

\begin{tabular}{ccccccccc}
\hline \hline & $\mathbf{1 2 , 1}$ & $\mathbf{1 2 , 3}$ & $\mathbf{1 2 , 6}$ & $\mathbf{9 , 1}$ & $\mathbf{9 , 3}$ & $\mathbf{6 , 1}$ & $\mathbf{6 , 3}$ & $\mathbf{3 , 1}$ \\
\hline Const. & $0.008^{* * *}$ & $0.005^{* *}$ & 0.002 & $0.008^{* * *}$ & $0.005^{* *}$ & $0.006^{* *}$ & $0.003^{* *}$ & $0.003^{*}$ \\
(s.e.) & $(0.003)$ & $(0.002)$ & $(0.002)$ & $(0.003)$ & $(0.002)$ & $(0.002)$ & $(0.001)$ & $(0.002)$ \\
Slope & $0.747^{* * *}$ & $0.710^{* * *}$ & $0.580^{* * *}$ & $0.716^{* * *}$ & $0.684^{* * *}$ & $0.583^{* * *}$ & $0.474^{* * *}$ & $0.511^{* * *}$ \\
(s.e.) & $(0.054)$ & $(0.059)$ & $(0.063)$ & $(0.063)$ & $(0.057)$ & $(0.067)$ & $(0.052)$ & $(0.081)$ \\
adj. R ${ }^{2}$ & 0.28 & 0.20 & 0.13 & 0.21 & 0.15 & 0.14 & 0.08 & 0.12 \\
Wald & {$[0.00]^{* * *}$} & {$[0.00]^{* * *}$} & {$[0.00]^{* * *}$} & {$[0.00]^{* * *}$} & {$[0.00]^{* * *}$} & {$[0.00]^{* * *}$} & {$[0.00]^{* * *}$} & {$[0.00]^{* * *}$} \\
\hline \hline
\end{tabular}




\section{Table 14: Expectations Hypothesis Test: Option-Implied Correlation - The Role of Jumps}

This table reports the results of the expectations hypothesis tests for the option-implied correlation of the

stocks of the S\&P 500. The regression equation is $\frac{1}{k} \sum_{i=0}^{k-1}\left(\rho_{i m,(i+1) m} \frac{q_{i m,(i+1) m}^{*}}{q_{0, k m}^{*}}-\rho_{0, m}\right)+\hat{\Delta}_{Q V}+\hat{\Delta}_{p q}=$ $a+b\left(\rho_{0, k m}-\rho_{0, m}\right)+\nu_{k m}$. In each column, the first number denotes the long horizon ( $k$ times $\left.m\right)$ and the second number denotes the short horizon $(m)$ (e.g., 12,1 means we have $k m=12$ and $m=1$ month(s)). The pure expectations hypothesis posits that the constant $a$ is zero and that the slope $b$ is one while the general expectations hypothesis requires only the latter. We test the individual hypotheses with $t$-tests and the joint hypothesis with a Wald test. All tests employ Newey \& West (1987) standard errors (s.e.) with $\mathrm{km}$ lags. We also present the results of a joint test of the expectations hypothesis along with bootstrapped p-values. ${ }^{*},{ }^{* *}$, and ${ }^{* * *}$ indicate significance at the $10 \%, 5 \%$, and $1 \%$ level, respectively.

\begin{tabular}{ccccccccc}
\hline \hline & $\mathbf{1 2 , 1}$ & $\mathbf{1 2 , 3}$ & $\mathbf{1 2 , 6}$ & $\mathbf{9 , 1}$ & $\mathbf{9 , 3}$ & $\mathbf{6 , 1}$ & $\mathbf{6 , 3}$ & $\mathbf{3 , 1}$ \\
\hline Const. & 0.040 & 0.036 & 0.015 & 0.043 & 0.039 & 0.021 & 0.011 & 0.014 \\
(s.e.) & $(0.051)$ & $(0.037)$ & $(0.021)$ & $(0.040)$ & $(0.027)$ & $(0.028)$ & $(0.015)$ & $(0.018)$ \\
Slope & $0.425^{*}$ & $0.215^{*}$ & 0.100 & $0.495^{*}$ & $0.296^{*}$ & $0.603^{*}$ & 0.583 & $0.463^{*}$ \\
(s.e.) & $(0.297)$ & $(0.401)$ & $(0.575)$ & $(0.276)$ & $(0.376)$ & $(0.223)$ & $(0.365)$ & $(0.307)$ \\
adj. R & 0.02 & 0.00 & 0.00 & 0.03 & 0.00 & 0.04 & 0.02 & 0.01 \\
Wald & 4.08 & 3.87 & 2.49 & 3.34 & 3.78 & 3.23 & 1.34 & 3.84 \\
p-value & {$[0.13]$} & {$[0.14]$} & {$[0.29]$} & {$[0.19]$} & {$[0.15]$} & {$[0.20]$} & {$[0.51]$} & {$[0.15]$} \\
\hline Joint & Pure & General & & & & & & \\
\hline Wald & 116.3 & 21.9 & & & & & & \\
p-value & {$[0.34]$} & {$[0.29]$} & & & & & & \\
\hline \hline
\end{tabular}




\title{
The Term Structure of Systematic and Idiosyncratic Risk
}

\author{
Fabian Hollstein ${ }^{\dagger}$, Marcel Prokopczuk ${ }^{\dagger}$, , and Chardin Wese Simen ${ }^{\ddagger}$
}

Online Appendix

JEL classification: G12, G11, G17

Keywords: Systematic risk, idiosyncratic risk, options, term structure, expectations hypothesis, model-free option-implied variance, implied correlation

\footnotetext{
${ }^{\dagger}$ School of Economics and Management, Leibniz University Hannover, Koenigsworther Platz 1, 30167 Hannover, Germany.

${ }^{\ddagger}$ ICMA Centre, Henley Business School, University of Reading, Reading, RG6 6BA, UK.
} 


\section{Table A1: Expectations Hypothesis Test: Option-Implied Variance - Firm-Fixed Effects}

This table reports the results of the expectations hypothesis tests for the model-free option-implied variance. In Panel A, we present the results for the S\&P 500 market index and Panel B shows the aggregated results for the individual stocks included in the $\mathrm{S} \& \mathrm{P} 500$. The regression equation is $\frac{1}{k} \sum_{i=0}^{k-1}\left(\sigma_{j, i m,(i+1) m}^{2}-\sigma_{j, 0, m}^{2}\right)=a_{j}+b_{j}\left(\sigma_{j, 0, k m}^{2}-\sigma_{j, 0, m}^{2}\right)+\nu_{j, k m}$. In each column, the first number denotes the long horizon ( $k$ times $m$ ) and the second number denotes the short horizon $(m)$ (e.g., 12,1 means we have $k m=12$ and $m=1$ month(s)). The pure expectations hypothesis posits that the constant $a$ is zero and that the slope $b$ is one while the general expectations hypothesis requires only the latter. We test the individual hypotheses with $t$-tests and the joint hypothesis with a Wald test. All tests employ a panel regression approach, allowing for firm-specific intercept estimates and using the two-way clustered standard errors of Cameron et al. (2011). ${ }^{*},{ }^{* *}$, and ${ }^{* * *}$ indicate significance at the $10 \%, 5 \%$, and $1 \%$ level, respectively. [share] denotes the percentage share of stocks for which the intercept is significantly different from zero at the $5 \%$ level.

\begin{tabular}{ccccccccc}
\hline \hline & $\mathbf{1 2 , 1}$ & $\mathbf{1 2 , 3}$ & $\mathbf{1 2 , 6}$ & $\mathbf{9 , 1}$ & $\mathbf{9 , 3}$ & $\mathbf{6 , 1}$ & $\mathbf{6 , 3}$ & $\mathbf{3 , 1}$ \\
\hline Const. & 0.014 & 0.007 & 0.002 & 0.014 & 0.006 & 0.011 & 0.004 & 0.006 \\
(s.e.) & $(0.008)$ & $(0.006)$ & $(0.005)$ & $(0.008)$ & $(0.005)$ & $(0.007)$ & $(0.004)$ & $(0.005)$ \\
[share $]$ & {$[0.52]$} & {$[0.34]$} & {$[0.19]$} & {$[0.49]$} & {$[0.27]$} & {$[0.44]$} & {$[0.18]$} & {$[0.30]$} \\
Slope & 0.948 & 0.939 & $0.798^{*}$ & 0.917 & 0.883 & $0.783^{* * *}$ & $0.670^{* * *}$ & $0.638^{* * *}$ \\
(s.e.) & $(0.070)$ & $(0.087)$ & $(0.110)$ & $(0.080)$ & $(0.089)$ & $(0.081)$ & $(0.060)$ & $(0.068)$ \\
adj. R & 0.36 & 0.22 & 0.12 & 0.30 & 0.17 & 0.24 & 0.11 & 0.18 \\
Wald & {$[0.00]^{* * *}$} & {$[0.00]^{* * *}$} & {$[0.00]^{* * *}$} & {$[0.00]^{* * *}$} & {$[0.00]^{* * *}$} & {$[0.00]^{* * *}$} & {$[0.00]^{* * *}$} & {$[0.00]^{* * *}$} \\
\hline \hline
\end{tabular}




\section{Table A2: Expectations Hypothesis Test: Systematic Risk - Firm-Fixed Effects}

This table reports the results of the expectations hypothesis tests for systematic risk. We show the aggregated results for the individual stocks included in the S\&P 500. The regression equation is $\frac{1}{k} \sum_{i=0}^{k-1}\left(\beta_{j, i m,(i+1) m}^{2} \sigma_{M, i m,(i+1) m}^{2}-\beta_{j, 0, m}^{2} \sigma_{M, 0, m}^{2}\right)+\hat{\Delta}_{\beta \sigma}+\hat{\Delta}_{\beta r}+\hat{\Delta}_{\epsilon}=a_{j}+$ $b_{j}\left(\beta_{j, 0, k m}^{2} \sigma_{M, 0, k m}^{2}-\beta_{j, 0, m}^{2} \sigma_{M, 0, m}^{2}\right)+\nu_{j, k m}$. In each column, the first number denotes the long horizon ( $k$ times $m$ ) and the second number denotes the short horizon $(m$ ) (e.g., 12,1 means we have $k m=12$ and $m=1$ month(s)). The pure expectations hypothesis posits that the constant $a$ is zero and that the slope $b$ is one while the general expectations hypothesis requires only the latter. We test the individual hypotheses with $t$-tests and the joint hypothesis with a Wald test. All tests employ a panel regression approach, allowing for firm-specific intercept estimates and using the two-way clustered standard errors of Cameron et al. (2011). ${ }^{*},{ }^{* *}$, and ${ }^{* * *}$ indicate significance at the $10 \%, 5 \%$, and $1 \%$ level, respectively. [share] denotes the percentage share of stocks for which the intercept is significantly different from zero at the $5 \%$ level.

\begin{tabular}{ccccccccc}
\hline \hline & $\mathbf{1 2 , 1}$ & $\mathbf{1 2 , 3}$ & $\mathbf{1 2 , 6}$ & $\mathbf{9 , 1}$ & $\mathbf{9 , 3}$ & $\mathbf{6 , 1}$ & $\mathbf{6 , 3}$ & $\mathbf{3 , 1}$ \\
\hline Const. & 0.014 & 0.007 & 0.003 & 0.013 & 0.007 & 0.013 & 0.006 & 0.008 \\
(s.e.) & $(0.008)$ & $(0.006)$ & $(0.005)$ & $(0.008)$ & $(0.006)$ & $(0.007)$ & $(0.004)$ & $(0.005)$ \\
[share $]$ & {$[0.48]$} & {$[0.38]$} & {$[0.24]$} & {$[0.46]$} & {$[0.31]$} & {$[0.45]$} & {$[0.31]$} & {$[0.37]$} \\
Slope & 1.191 & 1.353 & 1.029 & 1.143 & 1.175 & 0.948 & 0.963 & 0.759 \\
(s.e.) & $(0.164)$ & $(0.229)$ & $(0.376)$ & $(0.165)$ & $(0.229)$ & $(0.172)$ & $(0.215)$ & $(0.237)$ \\
adj. R & 0.23 & 0.15 & 0.04 & 0.20 & 0.11 & 0.15 & 0.07 & 0.07 \\
Wald & {$[0.00]^{* * *}$} & {$[0.00]^{* * *}$} & {$[0.00]^{* * *}$} & {$[0.00]^{* * *}$} & {$[0.00]^{* * *}$} & {$[0.00]^{* * *}$} & {$[0.00]^{* * *}$} & {$[0.00]^{* * *}$} \\
\hline \hline
\end{tabular}




\section{Table A3: Expectations Hypothesis Test: Idiosyncratic Variance - Firm-Fixed Effects}

This table reports the results of the expectations hypothesis tests for idiosyncratic variance. We show the aggregated results for the individual stocks included in the S\&P 500. The regression equation is $\frac{1}{k} \sum_{i=0}^{k-1}\left(\sigma_{\epsilon, j, i m,(i+1) m}^{2}-\sigma_{\epsilon, j, 0, m}^{2}\right)=a_{j}+b_{j}\left(\sigma_{\epsilon, j, 0, k m}^{2}-\sigma_{\epsilon, j, 0, m}^{2}\right)+\nu_{j, k m}$. In each column, the first number denotes the long horizon ( $k$ times $m$ ) and the second number denotes the short horizon $(m)$ (e.g., 12,1 means we have $k m=12$ and $m=1$ month(s)). The pure expectations hypothesis posits that the constant $a$ is zero and that the slope $b$ is one while the general expectations hypothesis requires only the latter. We test the individual hypotheses with $t$-tests and the joint hypothesis with a Wald test. All tests employ a panel regression approach, allowing for firm-specific intercept estimates and using the two-way clustered standard errors of Cameron et al. (2011). ${ }^{*},{ }^{* *}$, and ${ }^{* * *}$ indicate significance at the $10 \%, 5 \%$, and $1 \%$ level, respectively. [share] denotes the percentage share of stocks for which the intercept is significantly different from zero at the $5 \%$ level.

\begin{tabular}{ccccccccc}
\hline \hline & $\mathbf{1 2 , 1}$ & $\mathbf{1 2 , 3}$ & $\mathbf{1 2 , 6}$ & $\mathbf{9 , 1}$ & $\mathbf{9 , 3}$ & $\mathbf{6 , 1}$ & $\mathbf{6 , 3}$ & $\mathbf{3 , 1}$ \\
\hline Const. & 0.010 & 0.006 & 0.002 & 0.009 & 0.005 & 0.008 & 0.003 & 0.005 \\
(s.e.) & $(0.005)$ & $(0.004)$ & $(0.003)$ & $(0.005)$ & $(0.003)$ & $(0.004)$ & $(0.003)$ & $(0.003)$ \\
[share] & {$[0.54]$} & {$[0.39]$} & {$[0.21]$} & {$[0.53]$} & {$[0.33]$} & {$[0.49]$} & {$[0.23]$} & {$[0.36]$} \\
Slope & $0.782^{* * *}$ & $0.768^{* * *}$ & $0.701^{* * *}$ & $0.741^{* * *}$ & $0.676^{* * *}$ & $0.641^{* * *}$ & $0.516^{* * *}$ & $0.586^{* * *}$ \\
(s.e.) & $(0.058)$ & $(0.084)$ & $(0.100)$ & $(0.069)$ & $(0.081)$ & $(0.081)$ & $(0.092)$ & $(0.080)$ \\
adj. R ${ }^{2}$ & 0.25 & 0.16 & 0.10 & 0.20 & 0.10 & 0.16 & 0.05 & 0.13 \\
Wald & {$[0.00]^{* * *}$} & {$[0.00]^{* * *}$} & {$[0.00]^{* * *}$} & {$[0.00]^{* * *}$} & {$[0.00]^{* * *}$} & {$[0.00]^{* * *}$} & {$[0.00]^{* * *}$} & {$[0.00]^{* * *}$} \\
\hline \hline
\end{tabular}




\section{Table A4: Expectations Hypothesis Tests: Alternative Option-Implied Beta I}

This table reports the results of the expectations hypothesis tests for systematic and idiosyncratic risk. We show the aggregated results for the individual stocks included in the S\&P 500. For systematic risk (Panel A), the regression equation is $\frac{1}{k} \sum_{i=0}^{k-1}\left(\beta_{j, i m,(i+1) m}^{2} \sigma_{M, i m,(i+1) m}^{2}-\beta_{j, 0, m}^{2} \sigma_{M, 0, m}^{2}\right)+\hat{\Delta}_{\beta \sigma}+\hat{\Delta}_{\beta r}+\hat{\Delta}_{\epsilon}=$ $a_{j}+b_{j}\left(\beta_{j, 0, k m}^{2} \sigma_{M, 0, k m}^{2}-\beta_{j, 0, m}^{2} \sigma_{M, 0, m}^{2}\right)+\nu_{j, k m}$. For idiosyncratic variance (Panel B), the regression equation is $\frac{1}{k} \sum_{i=0}^{k-1}\left(\sigma_{\epsilon, j, i m,(i+1) m}^{2}-\sigma_{\epsilon, j, 0, m}^{2}\right)=a_{j}+b_{j}\left(\sigma_{\epsilon, j, 0, k m}^{2}-\sigma_{\epsilon, j, 0, m}^{2}\right)+\nu_{j, k m}$. We use the beta estimator of Skintzi \& Refenes (2005). In each column, the first number denotes the long horizon $(k$ times $\mathrm{m}$ ) and the second number denotes the short horizon $(\mathrm{m}$ ) (e.g., 12,1 means we have $\mathrm{km}=12$ and $m=1 \operatorname{month}(\mathrm{s}))$. The pure expectations hypothesis posits that the constant $a$ is zero and that the slope $b$ is one while the general expectations hypothesis requires only the latter. We test the individual hypotheses with $t$-tests and the joint hypothesis with a Wald test. All tests employ a panel regression approach using the two-way clustered standard errors of Cameron et al. (2011). ***, and *** indicate significance at the $10 \%, 5 \%$, and $1 \%$ level, respectively.

\section{Panel A. Systematic Risk}

\begin{tabular}{ccccccccc}
\hline \hline & $\mathbf{1 2 , 1}$ & $\mathbf{1 2 , 3}$ & $\mathbf{1 2 , 6}$ & $\mathbf{9 , 1}$ & $\mathbf{9 , 3}$ & $\mathbf{6 , 1}$ & $\mathbf{6 , 3}$ & $\mathbf{3 , 1}$ \\
\hline Const. & $0.014^{* * *}$ & $0.007^{*}$ & 0.003 & $0.013^{* * *}$ & $0.006^{*}$ & $0.012^{* * *}$ & $0.005^{* *}$ & $0.007^{* * *}$ \\
(s.e.) & $(0.005)$ & $(0.004)$ & $(0.003)$ & $(0.005)$ & $(0.003)$ & $(0.004)$ & $(0.002)$ & $(0.003)$ \\
Slope & 1.115 & 1.186 & 0.863 & 1.058 & 1.077 & 0.836 & $0.693^{* *}$ & $0.505^{* *}$ \\
(s.e.) & $(0.137)$ & $(0.188)$ & $(0.272)$ & $(0.140)$ & $(0.185)$ & $(0.145)$ & $(0.143)$ & $(0.205)$ \\
adj. R & 0.20 & 0.13 & 0.04 & 0.17 & 0.10 & 0.11 & 0.05 & 0.04 \\
Wald $^{2}$ & {$[0.00]^{* * *}$} & {$[0.02]^{* *}$} & {$[0.65]$} & {$[0.01]^{* * *}$} & {$[0.08]^{*}$} & {$[0.01]^{* *}$} & {$[0.01]^{* *}$} & {$[0.01]^{* * *}$} \\
\hline \hline
\end{tabular}

Panel B. Idiosyncratic Variance

\begin{tabular}{ccccccccc}
\hline \hline & $\mathbf{1 2 , 1}$ & $\mathbf{1 2 , 3}$ & $\mathbf{1 2 , 6}$ & $\mathbf{9 , 1}$ & $\mathbf{9 , 3}$ & $\mathbf{6 , 1}$ & $\mathbf{6 , 3}$ & $\mathbf{3 , 1}$ \\
\hline Const. & $0.009^{* * *}$ & $0.004^{* *}$ & 0.001 & $0.008^{* * *}$ & $0.004^{* *}$ & $0.007^{* * *}$ & $0.002^{* *}$ & $0.004^{* * *}$ \\
(s.e.) & $(0.002)$ & $(0.002)$ & $(0.001)$ & $(0.002)$ & $(0.001)$ & $(0.002)$ & $(0.001)$ & $(0.001)$ \\
Slope & $0.727^{* * *}$ & $0.664^{* * *}$ & $0.600^{* * *}$ & $0.686^{* * *}$ & $0.576^{* * *}$ & $0.593^{* * *}$ & $0.454^{* * *}$ & $0.512^{* * *}$ \\
(s.e.) & $(0.056)$ & $(0.083)$ & $(0.088)$ & $(0.068)$ & $(0.076)$ & $(0.083)$ & $(0.084)$ & $(0.078)$ \\
adj. R $\mathrm{R}^{2}$ & 0.27 & 0.14 & 0.10 & 0.23 & 0.09 & 0.19 & 0.06 & 0.17 \\
Wald & {$[0.00]^{* * *}$} & {$[0.00]^{* * *}$} & {$[0.00]^{* * *}$} & {$[0.00]^{* * *}$} & {$[0.00]^{* * *}$} & {$[0.00]^{* * *}$} & {$[0.00]^{* * *}$} & {$[0.00]^{* * *}$} \\
\hline \hline
\end{tabular}




\section{Table A5: Expectations Hypothesis Tests: Alternative Option-Implied Beta II}

This table reports the results of the expectations hypothesis tests for systematic and idiosyncratic risk. We show the aggregated results for the individual stocks included in the S\&P 500. For systematic risk (Panel A), the regression equation is $\frac{1}{k} \sum_{i=0}^{k-1}\left(\beta_{j, i m,(i+1) m}^{2} \sigma_{M, i m,(i+1) m}^{2}-\beta_{j, 0, m}^{2} \sigma_{M, 0, m}^{2}\right)+\hat{\Delta}_{\beta \sigma}+\hat{\Delta}_{\beta r}+\hat{\Delta}_{\epsilon}=$

$a_{j}+b_{j}\left(\beta_{j, 0, k m}^{2} \sigma_{M, 0, k m}^{2}-\beta_{j, 0, m}^{2} \sigma_{M, 0, m}^{2}\right)+\nu_{j, k m}$. For idiosyncratic variance (Panel B), the regression equation is $\frac{1}{k} \sum_{i=0}^{k-1}\left(\sigma_{\epsilon, j, i m,(i+1) m}^{2}-\sigma_{\epsilon, j, 0, m}^{2}\right)=a_{j}+b_{j}\left(\sigma_{\epsilon, j, 0, k m}^{2}-\sigma_{\epsilon, j, 0, m}^{2}\right)+\nu_{j, k m}$. We use the beta estimator of Kempf et al. (2015). In each column, the first number denotes the long horizon ( $k$ times $m$ ) and the second number denotes the short horizon $(m)$ (e.g., 12,1 means we have $k m=12$ and $m=1$ month(s)). The pure expectations hypothesis posits that the constant $a$ is zero and that the slope $b$ is one while the general expectations hypothesis requires only the latter. We test the individual hypotheses with $t$-tests and the joint hypothesis with a Wald test. All tests employ a panel regression approach using the two-way clustered standard errors of Cameron et al. (2011). ${ }^{*},{ }^{* *}$, and ${ }^{* * *}$ indicate significance at the $10 \%, 5 \%$, and $1 \%$ level, respectively.

\section{Panel A. Systematic Risk}

\begin{tabular}{ccccccccc}
\hline \hline & $\mathbf{1 2 , 1}$ & $\mathbf{1 2 , 3}$ & $\mathbf{1 2 , 6}$ & $\mathbf{9 , 1}$ & $\mathbf{9 , 3}$ & $\mathbf{6 , 1}$ & $\mathbf{6 , 3}$ & $\mathbf{3 , 1}$ \\
\hline Const. & $0.014^{* * *}$ & $0.007^{*}$ & 0.003 & $0.013^{* * *}$ & $0.006^{*}$ & $0.012^{* * *}$ & $0.005^{* *}$ & $0.007^{* * *}$ \\
(s.e.) & $(0.005)$ & $(0.004)$ & $(0.003)$ & $(0.005)$ & $(0.003)$ & $(0.004)$ & $(0.002)$ & $(0.003)$ \\
Slope & 1.103 & 1.167 & 0.822 & 1.048 & 1.061 & 0.826 & $0.683^{* *}$ & $0.496^{* *}$ \\
(s.e.) & $(0.137)$ & $(0.188)$ & $(0.269)$ & $(0.140)$ & $(0.185)$ & $(0.145)$ & $(0.141)$ & $(0.203)$ \\
adj. R $\mathrm{R}^{2}$ & 0.20 & 0.13 & 0.03 & 0.17 & 0.10 & 0.11 & 0.05 & 0.03 \\
Wald & {$[0.00]^{* * *}$} & {$[0.03]^{* *}$} & {$[0.63]$} & {$[0.01]^{* * *}$} & {$[0.09] *$} & {$[0.01]^{* *}$} & {$[0.01]^{* *}$} & {$[0.01]^{* * *}$} \\
\hline \hline
\end{tabular}

Panel B. Idiosyncratic Variance

\begin{tabular}{ccccccccc}
\hline \hline & $\mathbf{1 2 , 1}$ & $\mathbf{1 2 , 3}$ & $\mathbf{1 2 , 6}$ & $\mathbf{9 , 1}$ & $\mathbf{9 , 3}$ & $\mathbf{6 , 1}$ & $\mathbf{6 , 3}$ & $\mathbf{3 , 1}$ \\
\hline Const. & $0.009^{* * *}$ & $0.005^{* * *}$ & 0.002 & $0.008^{* * *}$ & $0.004^{* *}$ & $0.007^{* * *}$ & $0.002^{* *}$ & $0.004^{* * *}$ \\
(s.e.) & $(0.002)$ & $(0.002)$ & $(0.001)$ & $(0.002)$ & $(0.001)$ & $(0.002)$ & $(0.001)$ & $(0.001)$ \\
Slope & $0.734^{* * *}$ & $0.674^{* * *}$ & $0.607^{* * *}$ & $0.690^{* * *}$ & $0.582^{* * *}$ & $0.597^{* * *}$ & $0.455^{* * *}$ & $0.513^{* * *}$ \\
(s.e.) & $(0.056)$ & $(0.081)$ & $(0.087)$ & $(0.067)$ & $(0.076)$ & $(0.082)$ & $(0.083)$ & $(0.077)$ \\
adj. R ${ }^{2}$ & 0.28 & 0.15 & 0.10 & 0.23 & 0.10 & 0.20 & 0.06 & 0.17 \\
Wald & {$[0.00]^{* * *}$} & {$[0.00]^{* * *}$} & {$[0.00]^{* * *}$} & {$[0.00]^{* * *}$} & {$[0.00]^{* * *}$} & {$[0.00]^{* * *}$} & {$[0.00]^{* * *}$} & {$[0.00]^{* * *}$} \\
\hline \hline
\end{tabular}




\section{Table A6: Finite Sample Bias: Option-Implied Variance}

This table reports the results accounting for the potential finite sample bias in expectations hypothesis tests. In Panels $\mathrm{A}$ and $\mathrm{B}$, we show the results for the bias in coefficient estimates. We obtain the bias-corrected coefficient estimates by conducting an block-bootstrap of the dependent variable. We run 1,000 repetitions and report the simulated coefficients with supplement (sim) and report the bias in percentage points. For individual stocks, we report the median bias as well as the $10 \%$ and $90 \%$ quantiles $\left(\mathrm{q}^{0.1}\right.$ and $\left.\mathrm{q}^{0.9}\right)$. In Panels $\mathrm{C}$ and $\mathrm{D}$, we report the results for expectations hypothesis tests with a bootstrapped distribution of the test statistics. We use the bias-corrected coefficient estimates and simulate the dependent variable under the null of $a=0$ and $b=1$. We repeat this step 1,000 times and obtain distributions of the $t$ - and Wald statistics. The regression equation is $\frac{1}{k} \sum_{i=0}^{k-1}\left(\sigma_{j, i m,(i+1) m}^{2}-\sigma_{j, 0, m}^{2}\right)=a_{j}+b_{j}\left(\sigma_{j, 0, k m}^{2}-\sigma_{j, 0, m}^{2}\right)+\nu_{j, k m}$. In each column, the first number denotes the long horizon $(k$ times $m$ ) and the second number denotes the short horizon $(m)($ e.g., 12,1 means we have $k m=12$ and $m=1 \operatorname{month}(\mathrm{s}))$. The pure expectations hypothesis posits that the constant $a$ is zero and that the slope $b$ is one while the general expectations hypothesis requires only the latter. We test the individual hypotheses with $t$-tests and the joint hypothesis with a Wald test. We also present the results of a joint test of the expectations hypothesis along with bootstrapped p-values. ${ }^{*},{ }^{* *}$, and $^{* * *}$ indicate significance at the $10 \%, 5 \%$, and $1 \%$ level, respectively.

Panel A. Coefficient Bias - Market

\begin{tabular}{ccccccccc}
\hline \hline & $\mathbf{1 2 , 1}$ & $\mathbf{1 2 , 3}$ & $\mathbf{1 2 , 6}$ & $\mathbf{9 , 1}$ & $\mathbf{9 , 3}$ & $\mathbf{6 , 1}$ & $\mathbf{6 , 3}$ & $\mathbf{3 , 1}$ \\
\hline Const. & -0.003 & -0.002 & -0.001 & -0.003 & -0.002 & -0.002 & -0.001 & -0.001 \\
Const. (sim) & -0.003 & -0.002 & -0.001 & -0.003 & -0.002 & -0.002 & -0.001 & -0.001 \\
bias (in pp) & 0.003 & 0.003 & 0.001 & 0.005 & -0.002 & 0.001 & -0.003 & 0.006 \\
Slope & 1.042 & 1.060 & 1.198 & 0.981 & 0.964 & 0.873 & 0.862 & 0.745 \\
Slope (sim) & 1.040 & 1.059 & 1.198 & 0.979 & 0.961 & 0.871 & 0.860 & 0.747 \\
bias (in pp) & 0.146 & 0.152 & -0.063 & 0.171 & 0.235 & 0.141 & 0.191 & -0.236 \\
\hline \hline
\end{tabular}


Table A6: Finite Sample Bias: Option-Implied Variance (continued)

$\underline{\text { Panel B. Coefficient Bias - Stocks }}$

\begin{tabular}{ccccccccc}
\hline \hline & $\mathbf{1 2 , 1}$ & $\mathbf{1 2 , 3}$ & $\mathbf{1 2 , 6}$ & $\mathbf{9 , 1}$ & $\mathbf{9 , 3}$ & $\mathbf{6 , 1}$ & $\mathbf{6 , 3}$ & $\mathbf{3 , 1}$ \\
\hline Const. & 0.012 & 0.006 & 0.002 & 0.012 & 0.005 & 0.009 & 0.003 & 0.005 \\
Const. (sim) & 0.012 & 0.006 & 0.002 & 0.012 & 0.005 & 0.009 & 0.003 & 0.005 \\
bias (in pp) & -0.004 & 0.000 & -0.004 & -0.005 & -0.003 & -0.003 & -0.005 & 0.003 \\
Slope & 0.909 & 0.890 & 0.751 & 0.881 & 0.838 & 0.754 & 0.640 & 0.620 \\
Slope (sim) & 0.909 & 0.890 & 0.750 & 0.881 & 0.839 & 0.754 & 0.640 & 0.621 \\
bias (in pp) & -0.027 & -0.007 & 0.026 & -0.005 & -0.011 & 0.015 & -0.063 & -0.020 \\
\hline \hline
\end{tabular}

Panel C. Finite Sample Distributions - Market

\begin{tabular}{ccccccccc}
\hline \hline & $\mathbf{1 2 , 1}$ & $\mathbf{1 2 , 3}$ & $\mathbf{1 2 , 6}$ & $\mathbf{9 , 1}$ & $\mathbf{9 , 3}$ & $\mathbf{6 , 1}$ & $\mathbf{6 , 3}$ & $\mathbf{3 , 1}$ \\
\hline Const. & -0.003 & -0.002 & -0.001 & -0.003 & -0.002 & -0.002 & -0.001 & -0.001 \\
p-value & {$[0.724]$} & {$[0.740]$} & {$[0.719]$} & {$[0.741]$} & {$[0.755]$} & {$[0.746]$} & {$[0.741]$} & {$[0.718]$} \\
Slope & 1.042 & 1.060 & 1.198 & 0.981 & 0.964 & 0.873 & 0.862 & 0.745 \\
p-value & {$[0.849]$} & {$[0.856]$} & {$[0.709]$} & {$[0.911]$} & {$[0.894]$} & {$[0.485]$} & {$[0.554]$} & {$[0.270]$} \\
adj. R ${ }^{2}$ & 0.38 & 0.26 & 0.13 & 0.32 & 0.20 & 0.24 & 0.15 & 0.10 \\
Wald & 0.63 & 0.53 & 0.75 & 0.53 & 0.43 & 1.99 & 1.21 & 3.15 \\
p-value & {$[0.91]$} & {$[0.92]$} & {$[0.88]$} & {$[0.91]$} & {$[0.93]$} & {$[0.67]$} & {$[0.75]$} & {$[0.30]$} \\
\hline Joint & Pure & General & & & & & & \\
\hline Wald & 22.1 & 6.23 & {$[0.54]$} & & & & & \\
p-value & {$[0.59]$} & & & & & \\
\hline \hline
\end{tabular}

Panel D. Finite Sample Distributions - Stocks

\begin{tabular}{ccccccccc}
\hline \hline & $\mathbf{1 2 , 1}$ & $\mathbf{1 2 , 3}$ & $\mathbf{1 2 , 6}$ & $\mathbf{9 , 1}$ & $\mathbf{9 , 3}$ & $\mathbf{6 , 1}$ & $\mathbf{6 , 3}$ & $\mathbf{3 , 1}$ \\
\hline Const. & $0.012^{* *}$ & $0.006^{*}$ & 0.002 & $0.012^{* *}$ & $0.005^{*}$ & $0.009^{* *}$ & 0.003 & $0.005^{*}$ \\
p-value & {$[0.010]$} & {$[0.098]$} & {$[0.490]$} & {$[0.011]$} & {$[0.072]$} & {$[0.010]$} & {$[0.141]$} & {$[0.068]$} \\
Slope & 0.909 & 0.890 & $0.751^{* *}$ & 0.881 & $0.838^{*}$ & $0.754^{* * *}$ & $0.640^{* * *}$ & $0.620^{* * *}$ \\
p-value & {$[0.213]$} & {$[0.266]$} & {$[0.048]$} & {$[0.180]$} & {$[0.094]$} & {$[0.001]$} & {$[0.001]$} & {$[0.000]$} \\
adj. R $\mathrm{R}^{2}$ & 0.34 & 0.21 & 0.11 & 0.29 & 0.16 & 0.23 & 0.11 & 0.17 \\
Wald & $7.39^{* *}$ & 3.39 & 5.19 & $8.25^{* *}$ & 4.88 & $14.4^{* * *}$ & $36.4^{* * *}$ & $35.2^{* * *}$ \\
p-value & {$[0.04]$} & {$[0.24]$} & {$[0.12]$} & {$[0.03]$} & {$[0.11]$} & {$[0.00]$} & {$[0.00]$} & {$[0.00]$} \\
\hline \hline
\end{tabular}




\section{Table A7: Errors-In-Variables: Option-Implied Variance}

This table reports the results accounting for errors-in-variables in expectations hypothesis tests. We replace the independent variable with the fitted value of a regression on its first lag. The regression equation is $\frac{1}{k} \sum_{i=0}^{k-1}\left(\sigma_{j, i m,(i+1) m}^{2}-\sigma_{j, 0, m}^{2}\right)=a_{j}+b_{j}\left(\sigma_{M, 0, k m}^{2}-\sigma_{M, 0, m}^{2}\right)+\nu_{j, k m}$. In each column, the first number denotes the long horizon ( $k$ times $m$ ) and the second number denotes the short horizon $(m)$ (e.g., 12,1 means we have $k m=12$ and $m=1 \operatorname{month}(\mathrm{s})$ ). The pure expectations hypothesis posits that the constant $a$ is zero and that the slope $b$ is one while the general expectations hypothesis requires only the latter. We test the individual hypotheses with $t$-tests and the joint hypothesis with a Wald test. All tests employ Newey \& West (1987) standard errors (s.e.) with 4 lags. For the market and each stock, we average the coefficient estimates, standard errors, and p-values across sub-samples. We also present the results of a joint test of the expectations hypothesis along with bootstrapped p-values.In Panel B, we present the results of a panel regression on a constant using the two-way clustered standard errors of Cameron et al. (2011). ${ }^{*},{ }^{* *}$, and ${ }^{* * *}$ indicate significance at the $10 \%, 5 \%$, and $1 \%$ level, respectively.

Panel A. Option-Implied Variance - Market

\begin{tabular}{ccccccccc}
\hline \hline & $\mathbf{1 2 , 1}$ & $\mathbf{1 2 , 3}$ & $\mathbf{1 2 , 6}$ & $\mathbf{9 , 1}$ & $\mathbf{9 , 3}$ & $\mathbf{6 , 1}$ & $\mathbf{6 , 3}$ & $\mathbf{3 , 1}$ \\
\hline Const. & -0.004 & -0.003 & -0.002 & -0.003 & -0.002 & -0.003 & -0.001 & -0.002 \\
(s.e.) & $(0.004)$ & $(0.003)$ & $(0.002)$ & $(0.003)$ & $(0.002)$ & $(0.002)$ & $(0.001)$ & $(0.001)$ \\
Slope & 1.284 & 1.209 & 1.576 & 1.266 & 1.152 & 1.216 & 0.933 & 1.564 \\
(s.e.) & $(0.270)$ & $(0.337)$ & $(0.579)$ & $(0.227)$ & $(0.261)$ & $(0.193)$ & $(0.220)$ & $(0.350)$ \\
adj. R & 0.23 & 0.17 & 0.11 & 0.20 & 0.14 & 0.16 & 0.08 & 0.12 \\
Wald & 1.90 & 0.95 & 1.62 & 2.41 & 0.96 & 2.68 & 0.66 & 4.30 \\
p-value & {$[0.39]$} & {$[0.62]$} & {$[0.44]$} & {$[0.30]$} & {$[0.62]$} & {$[0.26]$} & {$[0.72]$} & {$[0.12]$} \\
\hline Joint & Pure & General & & & & & & \\
\hline Wald & 33.0 & 18.4 & & & & & & \\
p-value & {$[0.47]$} & {$[0.25]$} & & & & & & \\
\hline \hline
\end{tabular}

Panel B. Option-Implied Variance - Stocks

\begin{tabular}{ccccccccc}
\hline \hline & $\mathbf{1 2 , 1}$ & $\mathbf{1 2 , 3}$ & $\mathbf{1 2 , 6}$ & $\mathbf{9 , 1}$ & $\mathbf{9 , 3}$ & $\mathbf{6 , 1}$ & $\mathbf{6 , 3}$ & $\mathbf{3 , 1}$ \\
\hline Const. & $0.012^{* * *}$ & $0.006^{*}$ & 0.002 & $0.012^{* * *}$ & $0.005^{*}$ & $0.009^{* *}$ & 0.003 & $0.005^{*}$ \\
(s.e.) & $(0.005)$ & $(0.003)$ & $(0.003)$ & $(0.004)$ & $(0.003)$ & $(0.004)$ & $(0.002)$ & $(0.003)$ \\
Slope & 0.909 & 0.890 & $0.751^{* *}$ & 0.881 & $0.838^{*}$ & $0.754^{* * *}$ & $0.640^{* * *}$ & $0.620^{* * *}$ \\
(s.e.) & $(0.069)$ & $(0.088)$ & $(0.110)$ & $(0.078)$ & $(0.089)$ & $(0.078)$ & $(0.060)$ & $(0.065)$ \\
adj. R & 0.34 & 0.21 & 0.11 & 0.29 & 0.16 & 0.23 & 0.11 & 0.17 \\
Wald & {$[0.02]^{* *}$} & {$[0.18]$} & {$[0.07]^{*}$} & {$[0.02]^{* *}$} & {$[0.09]^{*}$} & {$[0.00]^{* * *}$} & {$[0.00]^{* * *}$} & {$[0.00]^{* * *}$} \\
\hline \hline
\end{tabular}

